\title{
Water oxidation in photosystem II
}

\author{
Wolfgang Lubitz ${ }^{1}\left(\mathbb{0} \cdot\right.$ Maria Chrysina ${ }^{1} \cdot$ Nicholas $\operatorname{Cox}^{2} \oplus$
}

Received: 13 November 2018 / Accepted: 20 May 2019 / Published online: 11 June 2019

(c) The Author(s) 2019

\begin{abstract}
Biological water oxidation, performed by a single enzyme, photosystem II, is a central research topic not only in understanding the photosynthetic apparatus but also for the development of water splitting catalysts for technological applications. Great progress has been made in this endeavor following the report of a high-resolution X-ray crystallographic structure in 2011 resolving the cofactor site (Umena et al. in Nature 473:55-60, 2011), a tetra-manganese calcium complex. The electronic properties of the protein-bound water oxidizing $\mathrm{Mn}_{4} \mathrm{O}_{\mathrm{x}} \mathrm{Ca}$ complex are crucial to understand its catalytic activity. These properties include: its redox state(s) which are tuned by the protein matrix, the distribution of the manganese valence and spin states and the complex interactions that exist between the four manganese ions. In this short review we describe how magnetic resonance techniques, particularly EPR, complemented by quantum chemical calculations, have played an important role in understanding the electronic structure of the cofactor. Together with isotope labeling, these techniques have also been instrumental in deciphering the binding of the two substrate water molecules to the cluster. These results are briefly described in the context of the history of biological water oxidation with special emphasis on recent work using time resolved X-ray diffraction with free electron lasers. It is shown that these data are instrumental for developing a model of the biological water oxidation cycle.
\end{abstract}

Keywords Photosystem II · Oxygen-evolving complex · Water binding · Triplet oxygen formation · EPR spectroscopy Quantum chemical calculations

\section{Introduction}

More than three billion years ago, the cyanobacteria evolved a light-driven enzyme that was able to split water into molecular oxygen and hydrogen. Biology couples this to the reduction of carbon dioxide $\left(\mathrm{CO}_{2}\right)$ to carbohydrates and in so doing stores the energy of the sun in energy-rich compounds with water acting as the electron source. We call this whole process photosynthesis and it represents the central metabolic pathway of the biosphere. While there exists a wide

Wolfgang Lubitz

wolfgang.lubitz@cec.mpg.de

Maria Chrysina

maria.chrysina@cec.mpg.de

Nicholas Cox

nick.cox@anu.edu.au

1 Max-Planck-Institut für Chemische Energiekonversion, Mülheim/Ruhr, Germany

2 Research School of Chemistry, The Australian National University, Canberra, Australia variety of photosynthetic organisms from cyanobacteria to algae and higher plants, the cellular machinery responsible for water splitting is unique and uses the same mechanism across all species.

A byproduct of biological water splitting is dioxygen $\left(\mathrm{O}_{2}\right)$ (Fig. 1). Its accumulation over the last billion years has led to the formation of the oxygen-rich atmosphere of our planet (Fischer et al. 2016; Hamilton et al. 2016). It has also caused build-up of the ozone layer in the stratosphere that provides an efficient shield against high-energy UV radiation from the sun, thus protecting and sustaining life on earth. The increase in the concentration of $\mathrm{O}_{2}$ in the atmosphere started about two and a half billion years ago (Bekker et al. 2004) and led to the 'great oxygenation event' (GOE), a catastrophe for most early life forms on earth which had no defense mechanism to cope with the toxic oxygen, leading to mass extinction. On the other hand, the presence of $\mathrm{O}_{2}$ in the atmosphere fostered the development of higher, aerobic life forms, i.e., organisms that evolved to use oxygen for their metabolism. Thus, without the earlier invention of oxygenic photosynthesis, the development of complex life 


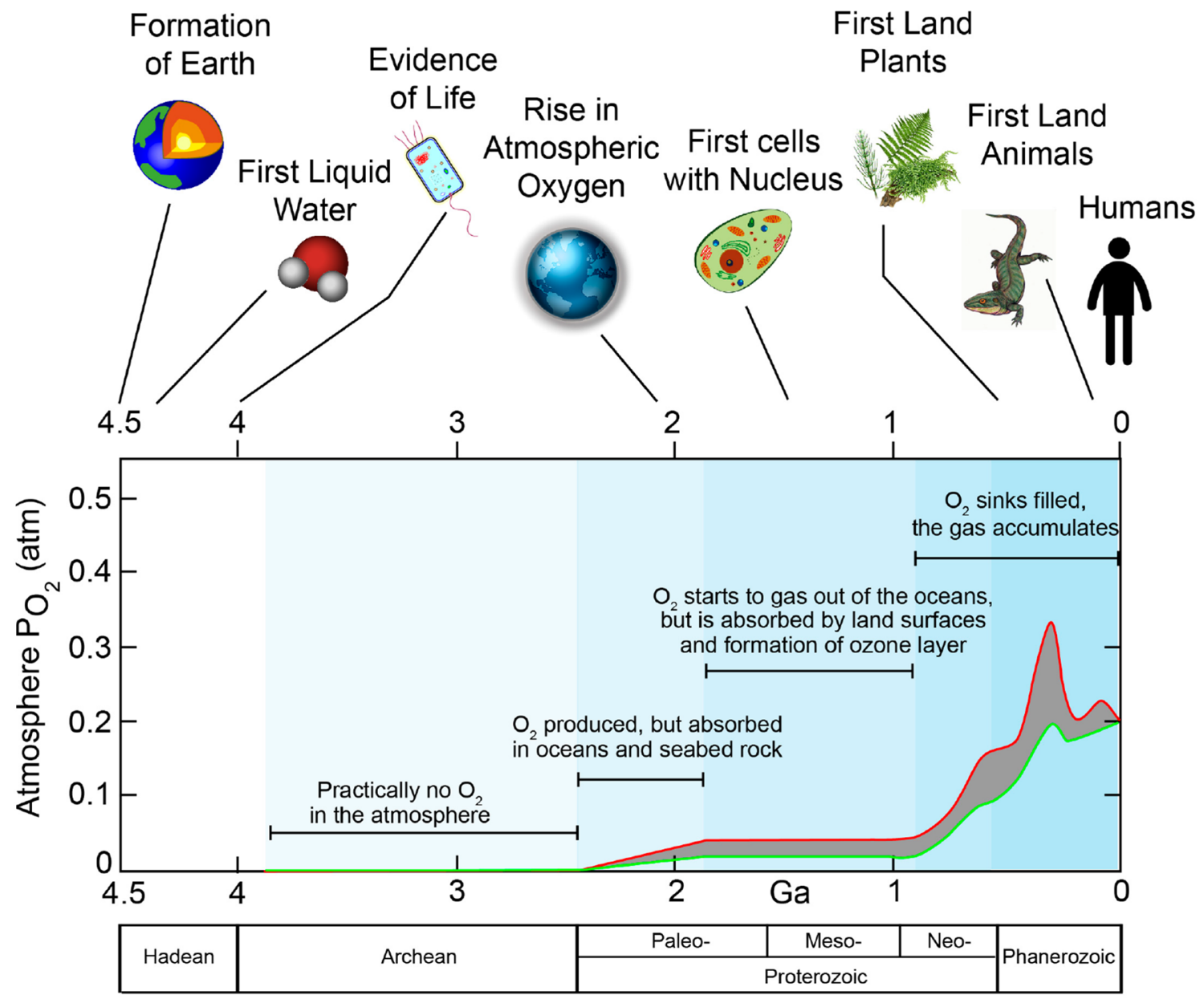

Fig. 1 Oxygen build-up in the Earth's atmosphere on a time scale of billions of years $(\mathrm{Ga})$ and some major events in the development of our planet. The red and green curves denote an upper and lower estimate of the oxygen in the atmosphere. Oxygenic photosynthesis started about $\approx 3.5 \mathrm{Ga}$ ago (Planavsky et al. 2014), the release of $\mathrm{O}_{2}$ in the atmosphere $\approx 2.4 \mathrm{Ga}$ ago (Bekker et al. 2004). The present level of $\mathrm{O}_{2}$ is $\approx 21 \%$ (Holland 2006) forms with cellular respiration-from simple vertebrates to human beings - would not have taken place. It is, therefore, not only of scientific but also of cultural value for mankind to understand how water oxidation and oxygen release functions in photosynthesis.

We benefit from photosynthesis in many ways. It is our only source of food and supplies us with much of our energy in the form of fossilized photosynthetic material—oil, coal and natural gas. Furthermore, it provides us with valuable natural materials like wood, paper, cotton, peat and biomass in general. Plants also contain many important bioactive materials that are used as drugs, in cosmetics, as natural dyes etc.

A basic understanding of the way how Nature stores energy and, in particular, uses sunlight to split water, could open future pathways to harvest and store the sun's abundant energy, satisfying the energy demands of society in a sustainable fashion i.e., by an "artificial photosynthesis" (acatech et al. 2018; Chabi et al. 2017; Collings and Critchley 2005; Cox and Lubitz 2013; Cox et al. 2015; Faunce et al. 2013; Gratzel 2005; McKone et al. 2016; Messinger et al. 2014; Nocera 2012, 2017; Wydrzynski and Hillier 2012). In the short review below the current knowledge of the principles of photosynthetic water oxidation in photosystem II of oxygenic organisms are described with special emphasis on the recent X-ray crystallographic data and the results obtained on the electronic structure of the water oxidizing cluster and the water binding and processing derived from advanced EPR techniques in combination with quantum chemical calculations. For a more extensive and detailed description of photosynthetic water oxidation in PS II the reader is referred to some recent reviews (Junge 2019; Pantazis 2018; Shen 2015; Vinyard and Brudvig 2017; Yano and Yachandra 2014). 


\section{The structure of photosystem II and the oxygen-evolving complex}

In oxygenic photosynthesis, sunlight is collected by the light-harvesting complexes (LHCs), specialized chlorophyll (and carotenoid) containing proteins, which show a large variation depending on the type of organism (Croce and van Amerongen 2014). The light energy is funneled to a reaction center $(\mathrm{RC})$ where charge separation across the photosynthetic membrane takes place. Two RCs-photosystem I and II (PS I, PS II) - work in tandem to create the redox potential necessary to drive the coupled reactions (Blankenship 2014). This process provides electrons with sufficiently negative potential needed to reduce $\mathrm{NADP}^{+}$ to NADPH, which can be considered "bound biological hydrogen". The electrons for this process originate from water oxidation that takes place in PS II. This process, and subsequent reactions, also generate a proton gradient across the photosynthetic membrane, which is used by the enzyme ATPase to produce ATP from ADP (Junge and Nelson 2015). In a different cell compartment, ATP and NADPH are then used to reduce $\mathrm{CO}_{2}$ to carbohydrates in the so-called dark reactions (Calvin-Benson cycle) (Calvin 1962).

Much of our current understanding of the photosynthetic machinery has come from high-resolution crystal structures of its constituents, particular photosystem I and II. The first crystal structure of a bacterial photosynthetic reaction center (BRC) was reported by Deisenhofer, Michel and Huber in the early eighties (Deisenhofer et al. 1985; Michel 1982, 1983)—who subsequently received the Nobel Prize in 1988 for this work. The structure of the simpler BRC provided a model for the functional core of PS I and PS II, in particular the processes of charge separation and progressive radical pair migration. It did not, however, provide any information on the water oxidizing complex (WOC) which is also called the oxygen-evolving complex (OEC), as this component is not found in the $\mathrm{BRC}$ that instead uses another electron source.

A crystal structure of a functional oxygen-evolving PS II core complex took almost two decades to be obtained. This was first achieved by the groups of Horst T. Witt and Wolfram Saenger in Berlin who reported the first crystallization of PS II from the cyanobacterium Synechococcus (S.) elongatus (later renamed Thermosynechococcus (T.) elongatus) and obtained a structure with $3.8 \AA$ A resolution in 2001 (Zouni et al. 2001). Although this first crystallographic structure provided valuable insight into the arrangement of the protein subunits and the cofactors of PS II it did not allow the positions of the atoms in the OEC, a tetranuclear manganese cluster, to be determined. This is because of radiation damage induced by the intense
X-ray beam used for X-ray diffraction (XRD) data collection in modern synchrotrons. X-ray absorption spectroscopy (XAS) experiments with varying beam intensity by Yano and coworkers have shown photoreduction of the oxidized Mn ions, disintegration of the complex and blurring of the electron density associated with the cluster (Yano et al. 2005). Before the advent of a PS II crystal structure with sufficient resolution attempts have been made to obtain models of the tetranuclear Mn cluster from spectroscopic experiments, in particular from XAS spectroscopy (Yachandra et al. 1996; Yano et al. 2006). In 2004 the group of James Barber (Imperial College London) presented an improved structure of PS II from S. elongatus at $3.5 \AA$ resolution (Ferreira et al. 2004). Based on their refined data, including anomalous diffraction to identify the $\mathrm{Ca}$, and also on previous EXAFS data (Robblee et al. 2001) the authors proposed a heterometallic cubane-type structure of the OEC, which contained a $\mathrm{Mn}_{3} \mathrm{Ca}$ unit along with a more distant dangler Mn. Such a "dangler model" had been proposed earlier by David Britt's group (UC Davis) based on constraints from EPR and ENDOR experiments and the distances obtained from EXAFS (Peloquin and Britt 2001; Peloquin et al. 2000). Finally, in 2011 the groups of Jian-Ren Shen (Okayama, Japan) and Nobuo Kamija (Osaka, Japan), who had reported a low resolution structure of PS II in 2003 (Kamiya and Shen 2003) published a significantly improved structure from Thermosynechococcus $(T$.) vulcanus at $1.9 \AA$ resolution, in which the atomic arrangement of the ions in the OEC was finally resolved (see below) (Umena et al. 2011). Subsequent theoretical studies showed that the actual oxidation state of the OEC in this structure was a mixture of overreduced states, not present in the catalytic cycle (Galstyan et al. 2012; Luber et al. 2011). The Shen group also succeeded in obtaining a structure with reduced radiation damage using femtosecond (fs) pulsed X-ray crystallography with a free electron laser (XFEL) (Suga et al. 2015). More recently, time resolved XFEL measurements (serial femtosecond crystallography-SFX) near ambient temperature has emerged as an important tool for the investigation of the various states of the catalytic cycle of the OEC (see below) (Kern et al. 2012, 2013, 2014, 2018; Kupitz et al. 2014; Suga et al. 2015, 2017).

In Fig. 2 the dimeric PS II protein is shown (Suga et al. 2015), located in the thylakoid membrane. Each monomer is made up of 20 protein subunits (in cyanobacteria). A few important ones are indicated in Fig. 2A. In Fig. 2B the cofactor arrangement in the D1/D2 subunits is shown-comprising chlorophylls $\left(\mathrm{P}_{\mathrm{D} 1}, \mathrm{P}_{\mathrm{D} 2}, \mathrm{Chl}_{\mathrm{D} 1}, \mathrm{Chl}_{\mathrm{D} 2}, \mathrm{Chl}_{\mathrm{D} 1}, \mathrm{Chlz}_{\mathrm{D} 2}\right)$, carotenoids $\left(\mathrm{Car}_{\mathrm{D} 1}, \mathrm{Car}_{\mathrm{D} 2}\right)$, pheophytins $\left(\mathrm{Pheo}_{\mathrm{D} 1}\right.$, Pheo $\left.\mathrm{D}_{2}\right)$, plastoquinones $\left(\mathrm{Q}_{\mathrm{A}}, \mathrm{Q}_{\mathrm{B}}\right)$, non-heme iron $(\mathrm{Fe})$ and also the WOC or OEC (Fig. 2C). This cubane-like cluster is bound in the PS II protein and comprises four $\mathrm{Mn}$ ions and one $\mathrm{Ca}$ ion linked by 

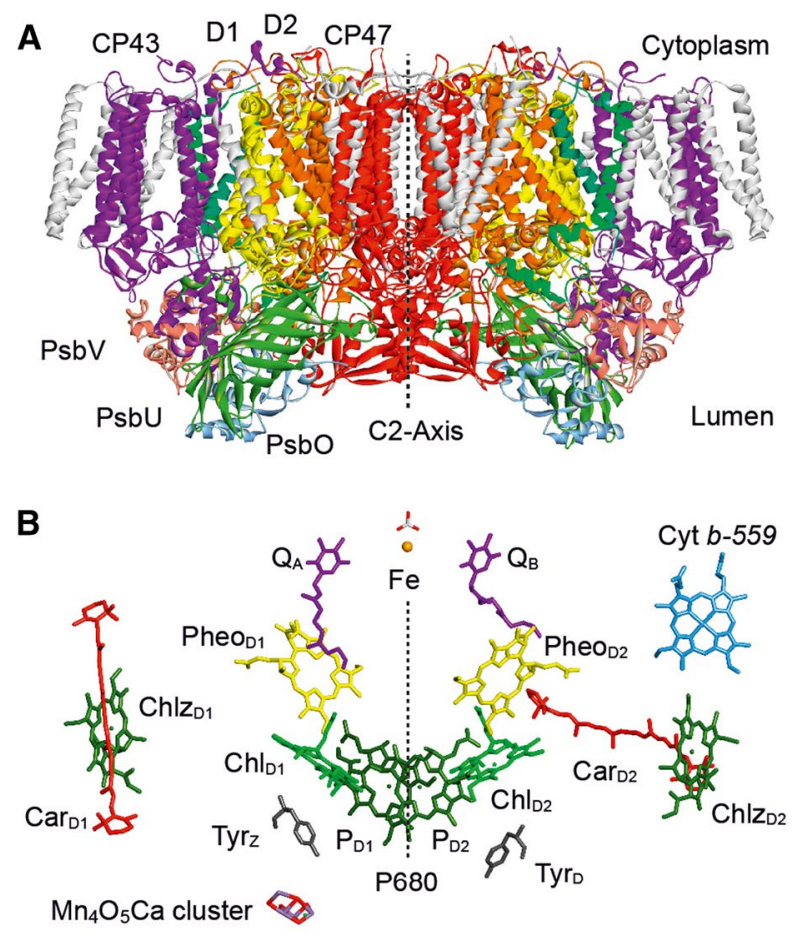
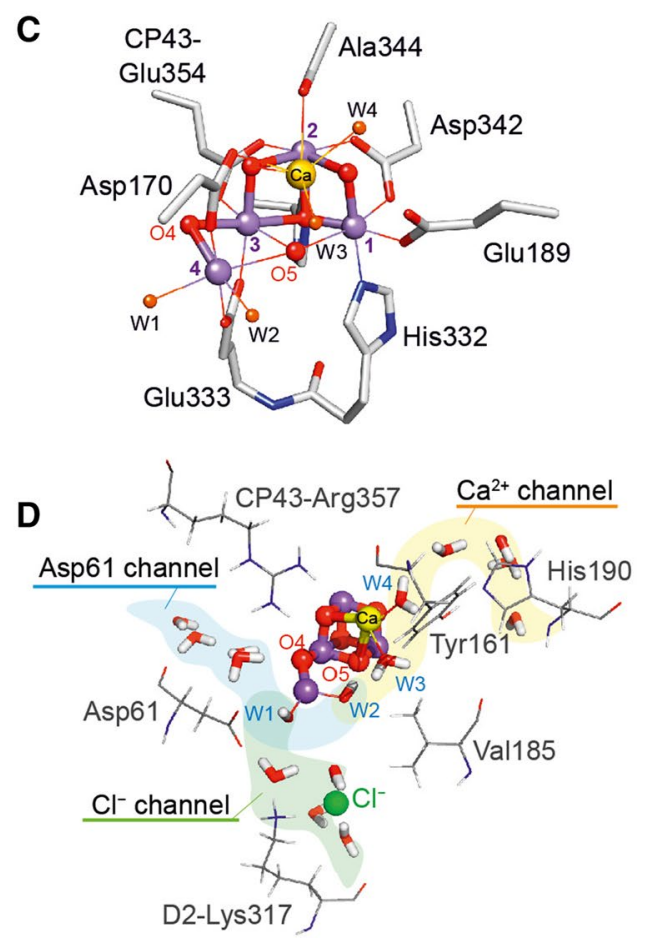

Fig. 2 X-ray crystallographic structure of photosystem II (PS II) from T. vulcanus. A View of the dimeric protein (molecular weight of the dimer $\approx 700 \mathrm{kDa}$ ); the two monomers are related to each other by a $\mathrm{C} 2$ axis. The most important subunits are indicated, CP43, CP47, in which the core antenna pigments are located; D1 and D2, which bind all pigments of the reaction center and all cofactors of the electron transport chain, and the small subunits PsbO, PsbU and PsbV, which stabilize the water splitting unit. The D1 protein (yellow) holds the active branch cofactors and the Mn cluster, the D2 protein (orange) the cofactors of the second pigment branch. B Pigment arrangement in one PS II monomer; the two branches are related by a pseudo-C2 axis (dotted line). Shown are the primary donor P680 (four chlorophylls: $\left.\mathrm{P}_{\mathrm{D} 1}, \mathrm{P}_{\mathrm{D} 2}, \mathrm{Chl}_{\mathrm{D} 1}, \mathrm{Chl}_{\mathrm{D} 2}\right)$, the two pheophytins $\left(\mathrm{Pheo}_{\mathrm{D} 1}\right.$, Pheo $\left._{\mathrm{D} 2}\right)$, the two plastoquinones $\left(Q_{\mathrm{A}}, Q_{\mathrm{B}}\right)$, and the non-heme iron Fe. Additional chlorophylls (Chlz) and carotenoids (Car), as well as

five oxygen bridges (six in the last stage of the catalytic cycle). Remarkably, it also binds four water molecules, two at the $\mathrm{Ca}$ and two at the dangling Mn4. The cluster is connected to the protein surface via specific channels for the efficient uptake of water, and the release of protons and molecular oxygen (Bondar and Dau 2012; Gabdulkhakov et al. 2009; Ho and Styring 2008; Linke and Ho 2014; Murray and Barber 2007; Retegan and Pantazis 2017; Saito et al. 2012; Umena et al. 2011; Vassiliev et al. 2012). For each PS II monomer about 1300 water molecules have been detected in the crystal structure (Umena et al. 2011); they are mostly found at the outside membrane region but quite a few are located inside of the PS II protein. The water access channels to the Mn cluster are two redox-active tyrosines $\left(\mathrm{Tyr}_{\mathrm{Z}}, \mathrm{Tyr}_{\mathrm{D}}\right)$ are also indicated. Next to the active branch (D1) and close to $\mathrm{Tyr}_{\mathrm{Z}} / \mathrm{P} 680$, the $\mathrm{Mn}_{4} \mathrm{O}_{5} \mathrm{Ca}$ cluster is located. C Structure of the water oxidizing $\mathrm{Mn}_{4} \mathrm{O}_{5} \mathrm{Ca}$ cluster in PS II with four Mn ions (Mn1 to Mn4, purple) and one Ca (yellow), bridged by oxygen ligands (red). Three Mn ions (1 to 3) and the $\mathrm{Ca}$ form a distorted cube bridged by oxygen ligands, the fourth $\mathrm{Mn}$ (Mn4) is dangling. Mn4 and the Ca carry two water molecules each (W1 to W4, orange). The coordination of the metal ions by amino acid ligands is also shown; for further details see (Suga et al. 2015; Umena et al. 2011). D Water channels leading to the OEC: Three channels have been localized. Note that also the essential chloride ion is shown in this picture (Suga et al. 2015; Umena et al. 2011). A second $\mathrm{Cl}^{-}$is found farther away from the OEC. It has been pointed out that the channels could be multi-functional

shown together with a few key amino acid ligands in Fig. 2D. The first channel is via the Asp 61 (shaded blue) the second via the $\mathrm{Ca}$ (shaded yellow) and a possible third one via the $\mathrm{Cl}^{-}$binding site (green). In all channels several water molecules have been found in the crystal structure (Ferreira et al. 2004; Gabdulkhakov et al. 2009; Ho and Styring 2008; Murray and Barber 2007; Saito et al. 2012; Umena et al. 2011; Vassiliev et al. 2012). $\mathrm{Cl}^{-}$depletion inhibits water oxidation; exchange of $\mathrm{Cl}^{-}$with $\mathrm{Br}^{-}$or $\mathrm{I}^{-}$slows the water oxidation kinetics (Damoder et al. 1986; Ono et al. 1987). The effect of these halogen anions is probably related to charge effects in the protein and proton egress. 


\section{Basic function of photosystem II: kinetics and energetics of water oxidation}

Light excitation of the reaction center of PS II, a multipigment assembly of four chlorophyll- $a$ and two pheophytin- $a$ molecules, leads to primary charge separation on a picosecond timescale. This is a single electron transfer process resulting in a charge-separated radical pair (RP) state comprising the radical cation $\mathrm{P} 680^{-+}$and the radical anion Pheo-- (Cardona et al. 2012). During primary charge separation, the positive charge is initially localized on the accessory chlorophyll $\mathrm{Chl}_{\mathrm{D} 1}$ and it is stabilized by subsequent transfer on $\mathrm{P}_{\mathrm{D} 1}$ (see Fig. 2A) (Groot et al. 2005; Holzwarth et al. 2006; Kammel et al. 2003). The primary acceptor Pheo is the pheophytin pigment bound to the D1 protein (Holzwarth et al. 2006). The oxidation potential of $\mathrm{P} 680^{-}$is estimated to +1.2 to $+1.3 \mathrm{~V}$, the highest known in biology (Rappaport et al. 2002). The primary RP P680.+ $\mathrm{Pheo}^{--}$is stabilized by subsequent electron/hole transfer steps. This is important as the radical cation can, in principle, oxidize neighboring chlorophylls, and the protein itself. To suppress both side and back reactions, nature has placed secondary donor/acceptors in close proximity to the primary RP. On the donor side of the protein (lumen), it is the redox-active tyrosine residue D1-Tyr161 (known as $\mathrm{Tyr}_{\mathrm{Z}}$ or $Y_{\mathrm{z}}$ ) next to P680+ that is able to quickly donate an electron to this species on a nanosecond (20-250 ns) time scale, thereby reducing the radical cation to its initial state P680. The tyrosine radical cation $Y_{\mathrm{z}}^{+}$is stabilized by losing a proton to the neighboring D1-His190 in a reversible fashion, forming a neutral tyrosine radical $\left(Y_{\mathrm{Z}}\right)$ (Berthomieu et al. 1998; Chu et al. 1995; Saito et al. 2011). $Y_{\mathrm{z}}$ in turn oxidizes the adjacent Mn cluster in 40-1600 $\mu$ s dependent on the $S_{i}$ transition (Babcock et al. 1976; Brettel et al. 1984; Dekker et al. 1984a; Haumann et al. 2005a; Karge et al. 1997; Klauss et al. 2012a; Noguchi et al. 2012; Rappaport et al. 1994; Razeghifard and Pace 1997). On the acceptor side of the protein (cytoplasm), the acceptor Pheo-- passes its electron to the bound plastoquinone molecules (to $Q_{\mathrm{A}}$ and subsequently to $Q_{\mathrm{B}}$ ). Reducing equivalents derived from this process are temporarily stored as reduced plastoquinol $\left(Q_{\mathrm{B}} \mathrm{H}_{2}\right)$, a mobile electron carrier, generated after two light absorption/charge separation and protonation events.

Other light-induced processes that occur in PS II are equally dangerous, for which nature has not found a perfect solution to circumvent them. This is the creation of triplet states, e.g., of the chlorophylls in the core antenna via intersystem crossing or in the RC via (triplet) radical pair recombination. While carotenoid molecules are present in PS II to suppress (quench) triplet chlorophyll formation, these states can still react with triplet oxygen $\left({ }^{3} \mathrm{O}_{2}\right)$ formed in the water oxidation process yielding singlet oxygen $\left({ }^{1} \mathrm{O}_{2}\right)$ (Macpherson et al. 1993). This very aggressive species can then react with the pigments and/or the protein, resulting in damage of the D1 protein subunit of the PSII supercomplex. The production of such reactive oxygen species (ROS) (Vass 2012) limits the lifetime of PS II to only 30 min under normal light conditions. Owing to its remarkable efficiency (the turnover time of the OEC is $\approx 2 \mathrm{~ms}$, that of the whole PS II $\approx 10 \mathrm{~ms}$ )(Vinyard and Brudvig 2017), it performs more than $10^{5}$ reaction cycles before it must be replaced. Fortunately, all organisms performing oxygenic photosynthesis have developed an efficient repair mechanism for the PS II supercomplex by the discrete replacement of the D1 protein (Nixon et al. 2010).

PS II thus acts as a water:plastoquinone oxidoreductase (Wydrzynski and Satoh 2005). The products are molecular (triplet) oxygen $\left({ }^{3} \mathrm{O}_{2}\right)$, protons and reduced plastohydroquinone. The light-induced process in PS II is very efficient, with a quantum yield of over $90 \%$ and an energy efficiency of about $20 \%$. This value is, however, strongly attenuated when all the subsequent processes are considered, such that the total biomass generated often contains only less than $1 \%$ of the original light energy input (Blankenship et al. 2011; Michel 2008).

It was discovered by Pierre Joliot almost half a century ago that PS II releases oxygen after four consecutive light flashes (Joliot et al. 1969) (Fig. 3A). This shows that four light-induced trans-membrane charge separation events are necessary before one $\mathrm{O}_{2}$ molecule is formed and released. This result is in agreement with the fact that the oxidation of two water molecules to produce a single $\mathrm{O}_{2}$ molecule is a four-electron process,

$2 \mathrm{H}_{2} \mathrm{O} \rightarrow \mathrm{O}_{2}+4 \mathrm{H}^{+}+4 \mathrm{e}^{-}$,

whereas the charge separation across the membrane is a oneelectron process. The oxidizing equivalents for the water oxidation reaction are stored transiently by the tetranuclear manganese cluster, an insight that came from Kok et al. (1970). His so-called Kok cycle (S-state cycle) of water oxidation, shown in Fig. 3B, comprises five distinct states, $S_{0}$ to $S_{4}$, which differ by the number of oxidizing equivalents transiently stored in the cofactor, as indicated by their subscript. The cycle is driven by four light absorption events $(\mathrm{h} \nu)$, by which electrons are withdrawn from the metal ions and protons are released to avoid the accumulation of positive charges and thus prevent a "coulombic explosion" of the cluster. $\mathrm{O}_{2}$ is released in a concerted reaction in the last reaction step with an equilibrium constant $k>1.0 \times 10^{7}$ (Nilsson et al. 2016). Kinetic measurements showed that the reaction times lie in the micro- to millisecond range ( $40 \mu$ s to $1.6 \mathrm{~ms}$ ) (Klauss et al. 2012a), see Fig. 3B; the complete cycle turns over in about $2 \mathrm{~ms}$. The kinetics of the proton release, which follow a 1:0:1:2 pattern (or 1:0:1:1:1) have 

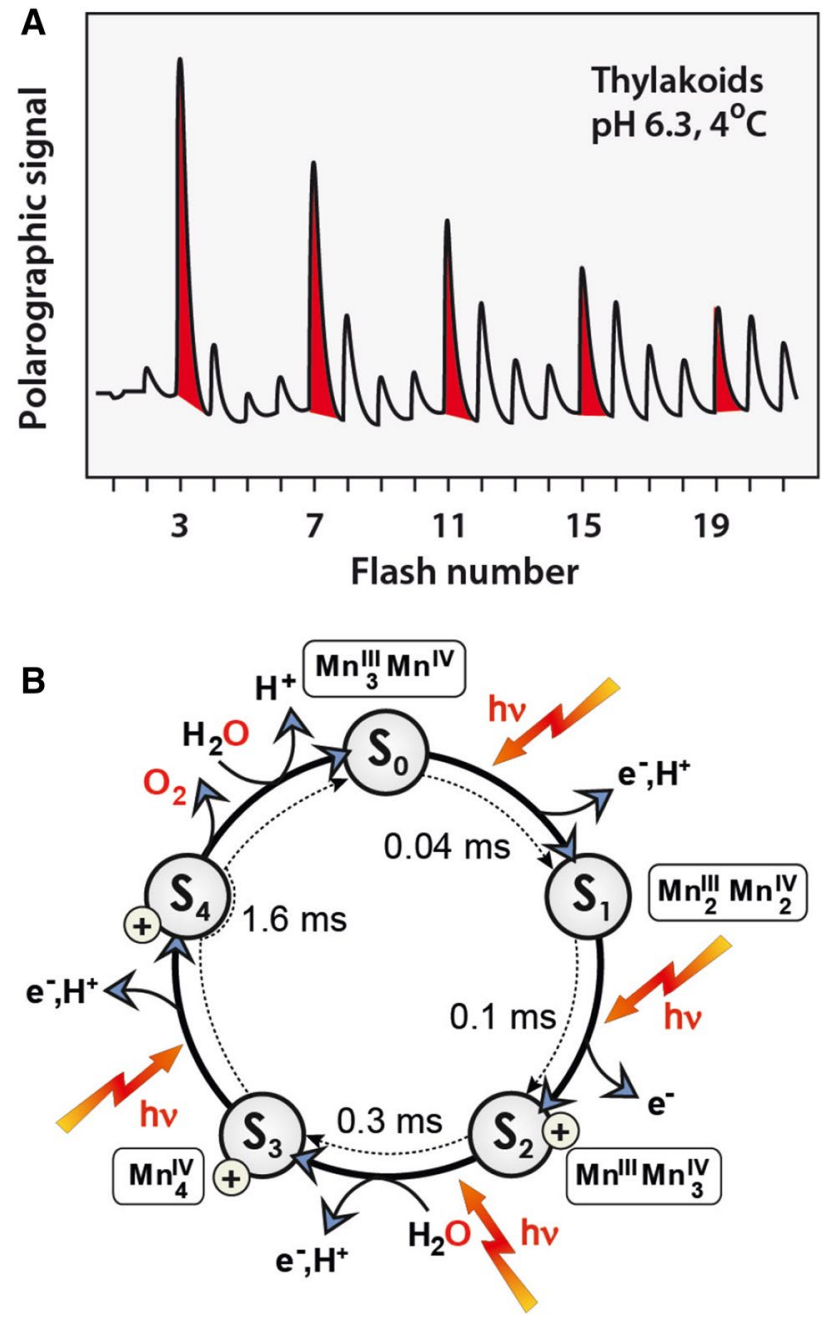

Fig. 3 A Release pattern of molecular oxygen $\left(\mathrm{O}_{2}\right)$ measured polarographically following successive light flashes of spinach thylakoids at $4{ }^{\circ} \mathrm{C}$ (Messinger and Renger 2008). Note that $\mathrm{O}_{2}$ release follows a 4-flash pattern (the starting dark stable state is $S_{1}$ ). The original experiment was performed by Pierre Joliot as early as 1969 (Joliot et al. 1969). B Water oxidation cycle (Kok cycle) (Kok et al. 1970) detailing the five basic $S$ states $\left(S_{0}\right.$ to $S_{4}$ ), the light-induced $1 \mathrm{e}^{-}$oxidation steps and the proton release pattern (Dau and Haumann 2008), the uptake of the two substrate waters (Hillier and Wydrzynski 2008) and the Mn oxidation states (Krewald et al. 2015) (vide infra). The reaction times for the single electron oxidation steps are also indicated (Klauss et al. 2012a). Note that here the " $S$ " stands for "state" and not for the electron spin quantum number $S$

also been determined, see (Dau and Haumann 2007; Klauss et al. 2012a, 2015; Schlodder and Witt 1999; Suzuki et al. 2009). The (alternating) electron and proton release led to an extended catalytic cycle for the water oxidation reaction in PS II with nine states that differ in their net electron and proton count (Klauss et al. 2012a, 2015; Perez-Navarro et al. 2016).

In this sequence, $\mathrm{Y}_{\mathrm{Z}}$ promotes both electron and proton transfer in the catalytic cycle displaying a dual function
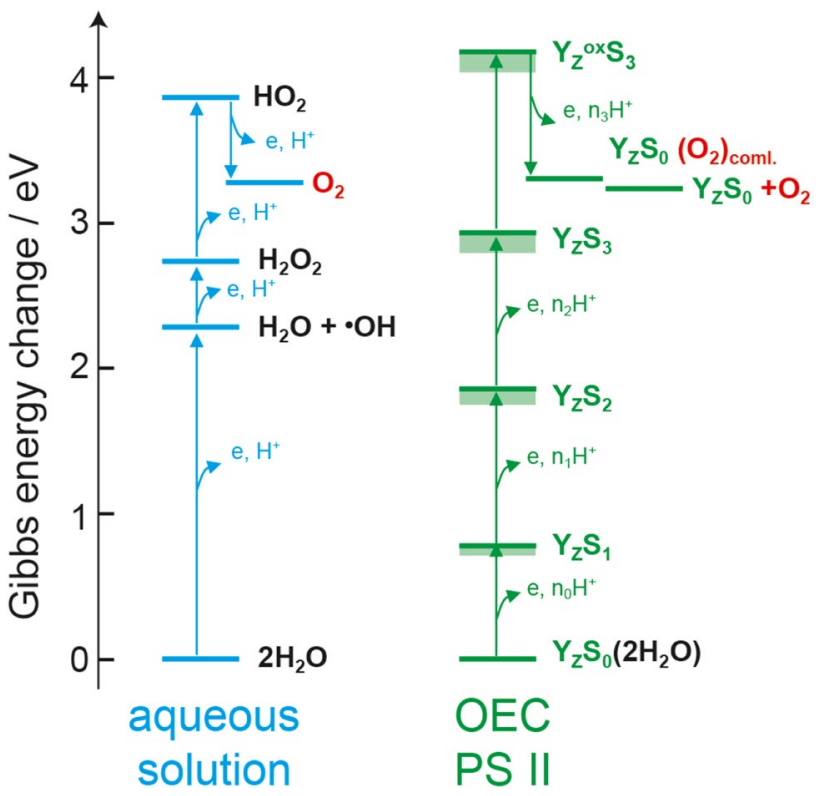

Fig. 4 Gibbs energy (in $\mathrm{eV}$ ) required to oxidize water stepwise in aqueous solution (left) and in the OEC of PS II (right). In particular the removal of the first electron from water (left) requires much energy $(>2 \mathrm{eV})$ that cannot be provided in a biological system. Thus, in the OEC, water is not oxidized by subsequent single electron removal from substrate water. Instead, it is the Mn cluster that is oxidized by four successive oxidation events; the two attached substrate water molecules release the protons (for charge neutrality), and $\mathrm{O}_{2}$ is released only in the last step after $\mathrm{O}-\mathrm{O}$ bond formation in a concerted reaction. Thereby, high-energy steps are avoided and the redox process is leveled. Figure adapted from (Messinger and Renger 2008)

(Bovi et al. 2013; Klauss et al. 2012b; Perez-Navarro et al. 2016). Between $S_{i}$ and $S_{i+1}$ states (for $i=0-3$ ) the short-lived $\mathrm{S}_{\mathrm{i}} \mathrm{Y}_{Z} \cdot$ intermediates exist. Studying these intermediates is critical for understanding the role of $Y_{Z}{ }^{\prime}$ in water oxidation and especially in proton removal from the $\mathrm{Mn}_{4} \mathrm{O}_{x} \mathrm{Ca}$ cluster (Boussac et al. 2008; Havelius et al. 2010; Nugent et al. 2002; Peloquin et al. 1998; Petrouleas et al. 2005; Retegan et al. 2014; Styring et al. 2012).

There are three interlinked reasons why the $\mathrm{Mn}_{4} \mathrm{O}_{\mathrm{x}} \mathrm{Ca}$ cluster functions in this way: (i) The energetic cost is significantly lowered by first storing oxidizing equivalents and then performing the four-electron chemistry; (ii) this sequence avoids the formation of reactive oxygen species (ROS) as intermediates resulting from partial oxidation of substrate water, which are highly reactive and can destroy the PS II protein complex; and (iii) proton release during charge accumulation leads to charge neutrality so that about the same oxidizing potential (oxidant $\mathrm{P} 60^{-}$) can be used for all $\mathrm{Mn}$ oxidation events. This is illustrated by the scheme in Fig. 4 (Messinger and Renger 2008). Here the Mn ions (and/or their ligands) are oxidized four times by the neighboring tyrosine $\mathrm{Y}_{\mathrm{Z}}$ triggered by four charge separation events in PS II before the cluster removes four electrons from two 
bound water molecules in a concerted reaction leading to $\mathrm{O}_{2}$ release and regeneration of the original starting state of the $\mathrm{Mn}_{4} \mathrm{O}_{\mathrm{x}} \mathrm{Ca}$ cluster. The Mn cluster thus acts as an interface and storage device between the very fast light reaction (ps time scale) and the slow catalytic reaction (ms time scale) of the 4-electron water oxidation chemistry, bridging a kinetic gap of nine orders of magnitude.

\section{The electronic structure of the $\mathrm{Mn}_{4} \mathrm{O}_{\mathrm{x}} \mathrm{Ca}$ cluster}

A detailed understanding of the catalytic process of water oxidation in PS II requires knowledge of the electronic structure, i.e., the distribution of the electrons in the cluster, in all consecutive reaction steps. The oxidation and spin states of the $\mathrm{Mn}$ ions, representing the total number and configuration of electrons in the Mn valence orbitals, give a basic description thereof. These together with the magnetic interactions between the spin-bearing Mn ions, depending to a large part on the metal ligands, provide a comprehensive picture of the respective electronic state, which governs the chemical and catalytic properties of each $\mathrm{S}$ state. Thus, the spin states provide information about how the structure of the cofactor evolves during the $S$-state cycle, for a recent review see (Krewald et al. 2016).

An experimental method to investigate the electronic structure of transition metal complexes is electron paramagnetic resonance (EPR) spectroscopy (Goldfarb and Stoll 2018; Schweiger and Jeschke 2001; Weil and Bolton 2007). It exploits a fundamental property of matter, which is that unpaired electrons have an intrinsic angular momentum (spin), which can be excited by microwave radiation in a magnetic field. The unpaired electron spin also interacts with other electron and nuclear spins as well as with local electric field gradients, making it a sensitive reporter of its chemical environment. It is thus analogous to other magnetic spectroscopies such as nuclear magnetic resonance (NMR). Since the $\mathrm{Mn}$ ions are open-shell species, i.e., exhibit orbitals with single electron occupancy, whereas most of the electrons of the protein and solvent surrounding are paired, the EPR signals of the $\mathrm{Mn}_{4} \mathrm{O}_{\mathrm{x}} \mathrm{Ca}$ cluster can be detected selectively. It has also been shown that all $\mathrm{S}$ states in the Kok cycle can be trapped (except for the elusive $S_{4}$ state) and that all exhibit paramagnetism (Haddy 2007).

The first EPR signal observed by Charles Dismukes in 1981 (Dismukes and Siderer 1981) came from the trapped $S_{2}$ state. Centered at $g \approx 2$ it included over 20 resolved lines and was thus called "multiline signal" (see Fig. 5). The structure is due to the coupling of the electron spin with the four ${ }^{55} \mathrm{Mn}$ nuclei $(I=5 / 2)$ via the electron nuclear hyperfine interaction. The EPR signal represents an effective low-spin ground state of $S_{\text {eff }}=1 / 2$ (Bencini and Gatteschi 1990). The

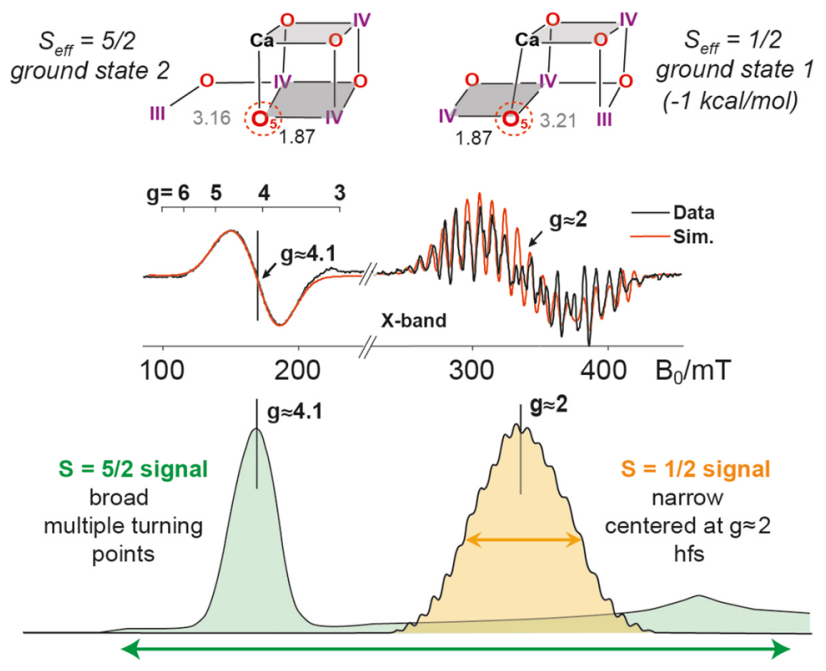

Fig. 5 Top: DFT-optimized structures of the $\mathrm{Mn}_{4} \mathrm{O}_{5} \mathrm{Ca}$ cluster in the $\mathrm{S}_{2}$ state (distances given in Ångström). Note that the "closed cubane" (left) and "open cubane" (right) structures have almost the same energy but different positions of the $\mathrm{Mn}^{\mathrm{III}}$ ion (Mn4 vs. Mn1, respectively) and different total (effective) spin ground states. This explains the two EPR signals observed for this state (shown below as first derivative X-band EPR spectra), with $g=4.1 \quad\left(S_{\text {eff }}=5 / 2\right.$; no hyperfine structure $)$ and $g=2\left(S_{\text {eff }}=1 / 2\right.$; multiline signal $)$. The bottom trace shows simulations of the two EPR absorption signals. Figure modified from (Krewald et al. 2016; Pantazis et al. 2012)

spin state depends on the oxidation state of the Mn ions, their geometry and in particular on the (bridging) ligands which connect the metal ions. These mediate antiferromagnetic or ferromagnetic exchange interactions between the $\mathrm{Mn}$ ions leading to either a low-spin state, minimizing the number of unpaired electrons, or a high-spin state, maximizing the number of unpaired electrons. The studies of the groups of Ono and Kusunoki on oriented PS II membranes and theoretical investigations (Hasegawa et al. 1998, 1999) and subsequent advanced EPR studies from the Britt (UC Davis) (Britt et al. 2000, 2004; Peloquin et al. 2000) and Lubitz (MPI Mülheim) laboratories (Cox et al. 2011; Kulik et al. 2005a, b, 2007; Lohmiller et al. 2012, 2014; Su et al. 2011) further constrained all four ${ }^{55} \mathrm{Mn}$ hyperfine tensors in the $S_{2}$ state and allowed the spin coupling in the tetranuclear manganese cluster to be interrogated. These data together with results collected on the $S_{0}$ state, which also resolves a multiline signal (Ahrling et al. 1997; Kulik et al. 2005b, 2007; Lohmiller et al. 2017; Messinger et al. 1997), and density functional theory calculations allowed the local oxidation states and set of coupling pathways to be determined (Ames et al. 2011; Krewald et al. 2013, 2015, 2016; Pantazis et al. 2012, 2009). The oxidation state assignment for the $\mathrm{S}_{2}$ state, which comes from this analysis, is shown in Fig. 5 (top), i.e., $\mathrm{Mn}_{4}$ (III, IV, IV, IV). According to the low oxidation scheme $S_{0}$ includes a $\mathrm{Mn}^{\mathrm{II}}$ (Kolling et al. 2012; Pace et al. 1991; Terrett et al. 2016), but this was excluded 
by the ${ }^{55} \mathrm{Mn}$ ENDOR experiments and analysis of the $\mathrm{S}_{0}$ state (Kulik et al. 2005b, 2007; Lohmiller et al. 2017). The reader interested in details on how the electronic configuration of a polynuclear Mn cluster, especially the $\mathrm{Mn}_{4} \mathrm{CaO}_{5}$, can be probed by EPR spectroscopy and double resonance techniques in relation with calculations of magnetic properties by quantum mechanical methods is referred to the following review (Lohmiller et al. 2013). Additional support for the high oxidation state scheme has come from the detection of ${ }^{14} \mathrm{~N}(I=1),{ }^{2} \mathrm{H}(I=1)$ and ${ }^{13} \mathrm{C}(I=1 / 2)$ hyperfine couplings of the $S_{2}$ state using ESEEM and ENDOR techniques performed by the group of R. D. Britt (Britt et al. 1989; Marchiori et al. 2018; Perez-Navarro et al. 2013; Oyala et al. 2015; Stich et al. 2011; Stull et al. 2010); see also (Lohmiller et al. 2017; Perez-Navarro et al. 2013). X-ray spectroscopies also agree with this assignment (Chatterjee et al. 2016; Zaharieva et al. 2016a, b). These studies rule out the alternative lower oxidation state models for the manganese cluster (Kolling et al. 2012; Pace et al. 1991) that are, however, still discussed in the literature (Chen et al. 2018; Terrett et al. 2016).

In the $\mathrm{S}_{2}$ state, in addition to the low-spin $S_{\text {eff }}=1 / 2$ form showing the characteristic multiline signal around $g \approx 2$, the cluster can also be found in a high-spin $S_{\text {eff }}=5 / 2$ state under certain conditions. This is evident from an EPR signal around $g=4.1$ (see Fig. 5), which has been observed earlier by several research groups (Boussac et al. 1996; Casey and Sauer 1984; Haddy et al. 2004; Zimmermann and Rutherford 1984). Pantazis et al. could show computationally that the two electronic structures are a direct consequence of two different spatial conformations of the manganese cluster, namely a "closed cubane" $\left(S_{\text {eff }}=5 / 2\right)$ and an "open cubane" $\left(S_{\text {eff }}=1 / 2\right)$ form, which have almost the same energy (Bovi et al. 2013; Isobe et al. 2012; Pantazis et al. 2012). In these two structures one of the oxygen bridges, O5, is occupying different positions. In turn this also led to a change of the $\mathrm{Mn}^{\mathrm{III}}$ position (Jahn-Teller ion) and thus of the open coordination site of the cluster resulting in a change of the precise electronic properties of the cofactor. EXAFS data also support this model (Chatterjee et al. 2019). This shows that the effective spin $S_{\text {eff }}$ is a crucial parameter for describing a particular state of the cluster and assigning it a spatial structure. It is postulated that $\mathrm{O} 5$ has not a fixed position but toggles between two structures in the dynamic $S_{2}$ state, which is important for the water binding and the catalytic mechanism (see below).

Modifications of the $\mathrm{Mn}_{4} \mathrm{O}_{\mathrm{x}} \mathrm{Ca}$ cluster, such as exchange of $\mathrm{Ca}^{2+}$ with $\mathrm{Sr}^{2+}$ (Boussac and Rutherford 1988; Boussac et al. 2015; Chu et al. 2000; Cox et al. 2011; Koua et al. 2013; Yachandra and Yano 2011), its complete removal (Boussac et al. 1989; Lohmiller et al. 2012; Styring et al. 2003; Vrettos et al. 2001b) and the binding of small molecules (Beck et al. 1986; Perez-Navarro et al. 2013; Oyala et al. 2015; Oyala et al. 2014; Retegan and Pantazis 2016; Su et al. 2011), provided further insight into the conformation and number of ligands of individual $\mathrm{Mn}$ ions (coordination geometry) and substrate access in the $S_{2}$ state. Upon Ca depletion water oxidation functionality is lost, but the $S_{2}$ state $\left(S_{2}{ }^{\prime}\right)$ is still formed (Boussac et al. 1989, 1990). Interestingly, the EPR and ${ }^{55} \mathrm{Mn}$ ENDOR data of $\mathrm{S}_{2}{ }^{\prime}$ show that the calcium has no substantial effect on the magnetic parameters of the $S_{2}$ state; this ion is thus not crucial for maintaining the electronic structure of the tetranuclear $\mathrm{Mn}$ cluster (Lohmiller et al. 2012). Instead, it might serve as stage for the delivery of water molecules to the reaction site (Nakamura et al. 2016; Service et al. 2014; Ugur et al. 2016), affect the function of $Y_{\mathrm{Z}}$, (Miqyass et al. 2008; Retegan et al. 2014) and introduce some structural flexibility allowing the cofactor to toggle between the different motifs of the open and closed cubane structures (see Fig. 5). The interactions of small molecules which mimic the substrate water (methanol, ammonia) also support this potential role for $\mathrm{Ca}^{2+}$. These molecules associate with the $\mathrm{Ca}^{2+}$ and Asp61 water channels that lead to the $\mathrm{Mn}_{4} \mathrm{O}_{\mathrm{x}} \mathrm{Ca}$ cofactor (Marchiori et al. 2018; Navarro et al. 2013; Oyala et al. 2014; Retegan and Pantazis 2016; Schraut and Kaupp 2014) (see Fig. 2D). In addition, both of these molecules reduce turnover efficiency; these results implicate that at least one (or possibly both) of these channels are involved in substrate delivery.

The EPR measurements have been extended to the $S_{3}$ state. These results are of particular importance since this is the last metastable state prior to $\mathrm{O}-\mathrm{O}$ bond formation and $\mathrm{O}_{2}$ release. The EPR signal of the $\mathrm{S}_{3}$ state has first been reported to originate from a ground state with an integer spin of $S_{\text {eff }}=3$ by the groups of Petrouleas (Sanakis et al. 2008) and Boussac (Boussac et al. 2009). Recent pulse high field (W-band) EPR experiments by Cox et al. (see Fig. 6A) corroborated this assignment and directly proved that the effective spin state is indeed $S_{\text {eff }}=3$ by measuring the Rabi oscillations via a spin nutation experiment (Cox et al. 2014). In addition ${ }^{55} \mathrm{Mn}$ ELDOR-detected-NMR (EDNMR) experiments at W-band could successfully be performed showing that in the $\mathrm{S}_{3}$ state all $\mathrm{Mn}$ ions are in the $\mathrm{Mn}^{\mathrm{IV}}$ state $\mathrm{Mn}_{4}$ (IV,IV,IV,IV) and octahedrally coordinated. Thus, no ligand oxidation takes place as previously proposed (Kawashima et al. 2018; Messinger et al. 2001). The results also show that a sixth ligand is binding to the open coordination site of the $\mathrm{Mn}^{\mathrm{III}}$ present in the $\mathrm{S}_{2}$ state when it is oxidized. This ligand is most probably the second substrate water molecule which also loses a proton in the $S_{2} \rightarrow S_{3}$ transition. Data from XAS, XES and FTIR further support these finding (Noguchi 2008; Sakamoto et al. 2017; Zaharieva et al. 2016a, b). Mn oxidation in the $\mathrm{S}_{2}$ to $\mathrm{S}_{3}$ transition has been proposed by Dekker (Dekker et al. 1984a, b) and Ono (Ono et al. 1992) and substantiated by Dau and coworkers (Haumann et al. 2005a, b). It has been included in mechanistic models (Pecoraro et al. 

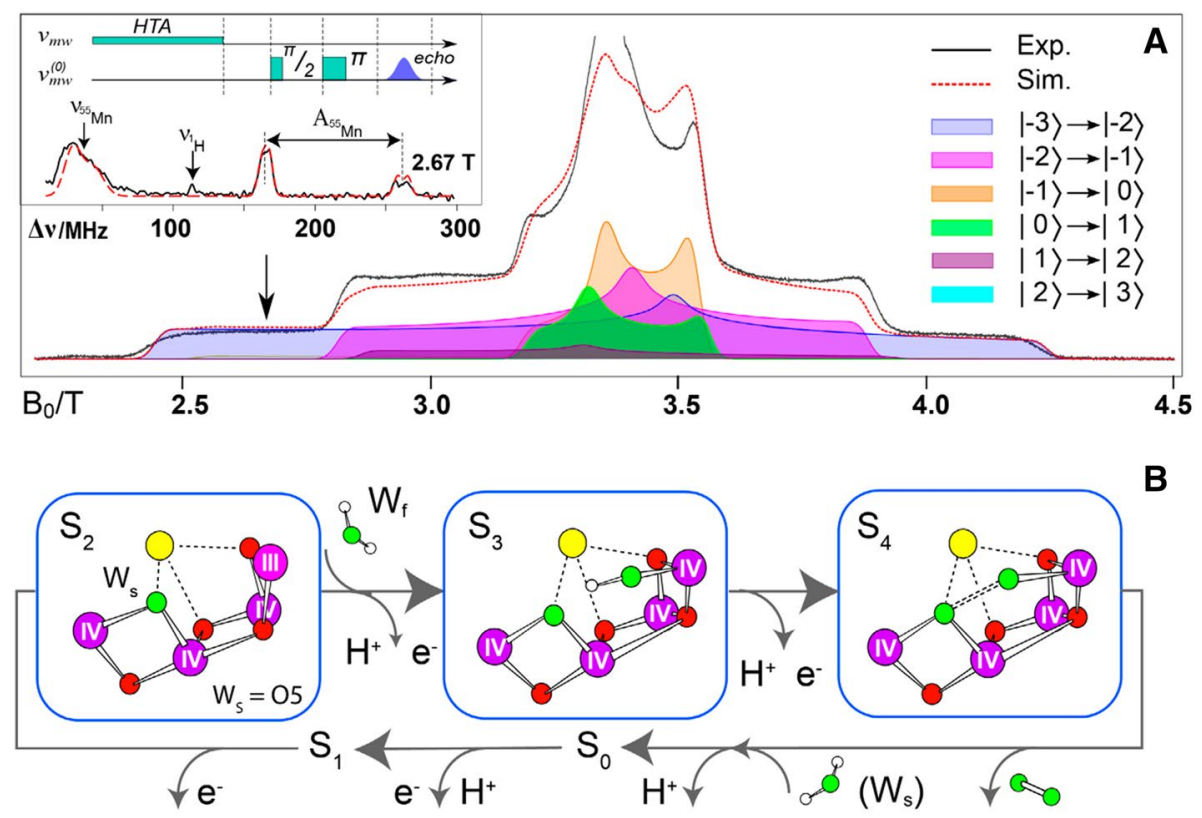

Fig. $6 \mathrm{~A}$ W-band EPR spectrum of the OEC in the $S_{3}$ state in PS II of $T$. elongatus ( $S_{3}-S_{1}$ light-dark difference spectrum) characteristic of an $S_{\text {eff }}=3$ ground state. The red-dashed line shows a simulation with $g$ and fine structure (zero field splitting) parameters D and E/D; the shaded curves show the contributions of the allowed EPR transitions to the simulated powder spectrum, the color code is indicated.

1998; Vrettos et al. 2001a) and has also theoretically been supported by Siegbahn (Siegbahn 2009). Very recently, SFX data have shown additional electron density acquired during the $S_{2}$ to $S_{3}$ transition, consistent with the binding of a light atom (e.g., an oxo or hydroxyl ligand) in the manganese cluster (Kern et al. 2018; Suga et al. 2017).

The magnetic resonance experiments described above together with theoretical calculations allowed a reliable characterization of the $S_{0}, S_{2}$ and $S_{3}$ states with respect to oxidation and spin states of individual ions and their spin coupling in the tetranuclear Mn cluster summarized by Krewald et al. (2015, 2016). Together with information about binding of the two substrate water molecules described below spatial models of the $\mathrm{S}$ states could be obtained that form the basis for developing a catalytic mechanism for the OEC (Fig. 8).

\section{Identification of the substrate water molecules in water oxidation}

Knowledge of the binding and dynamics of the substrate water molecules is crucial for formulating the reaction mechanism of photosynthetic water oxidation. Candidates for substrate waters, besides the four $\mathrm{H}_{2} \mathrm{O} / \mathrm{OH}^{-}$molecules (Fig. 2C) directly attached to the cluster (Ames et al. 2011; Suga et al. 2015; Umena et al. 2011), are oxygen bridges within the cluster as well as possible water molecules
As insert a ${ }^{55} \mathrm{Mn}$ EDNMR spectrum is shown obtained at the EPR position indicated by the arrow. The used EDNMR pulse sequence is given above. Figure modified from (Cox et al. 2014). B Structure of the manganese cluster proceeding through the $S_{2} \rightarrow \mathrm{S}_{3} \rightarrow S_{4}$ states including water $W_{\mathrm{f}}$ binding, proton release and $\mathrm{O}_{2}$ formation as suggested by magnetic spectroscopy

binding at a later point in the catalytic cycle. Apart from $\mathrm{X}$-ray diffraction spectroscopic techniques are used to investigate water binding, in particular EPR (Cox et al. 2013b; Fiege et al. 1996; Kawamori et al. 1989; McConnell et al. 2012; Nagashima and Mino 2013; Rapatskiy et al. 2012) and vibrational (infrared) spectroscopy (Debus 2014, 2015; Kim et al. 2018; Kim and Debus 2017; Nakamura et al. 2016; Noguchi 2008; Sakamoto et al. 2017; Suzuki et al. 2008). These are used in conjunction with time-resolved mass spectrometry (MIMS) which detects the uptake of $\mathrm{H}_{2}^{18} \mathrm{O}$ labeled water into the product $\mathrm{O}_{2}$; for a comprehensive review on the identification of possible water substrates by MIMS see (Cox and Messinger 2013). MIMS experiments showed that the two substrate water molecules exchange at different rates in all of the $\mathrm{S}$ states (Hillier and Wydrzynski 2000, 2004, 2008). The more slowly exchanging water $\left(W_{\mathrm{s}}\right)$ has an exchange rate of the order of seconds (Messinger et al. 1995) while the faster exchanging water $\left(W_{\mathrm{f}}\right)$ has an exchange rate of milliseconds (Hillier et al. 1998) (see Fig. 3B). The observation of two rates implies that the two substrates bind at two chemically distinct sites. They also demonstrate that the $\mathrm{O}-\mathrm{O}$ bond is not formed until the $\left(S_{4}\right)$ state is reached. Interestingly, it was recently observed that during the lifetime of the $S_{3} Y_{Z}$ state, that lies between $S_{3}$ and the elusive $S_{4}$ state while the $Y_{Z}$ radical exists, the water exchange is slowing 
down, which may suggest that the two oxygen species are "arrested" in a bonding formation (Nilsson et al. 2014).

For the detection of substrate water molecules, EPR spectroscopy makes use of interactions with nuclear spins, e.g. ${ }^{2} \mathrm{H}\left(\right.$ in ${ }^{2} \mathrm{H}_{2} \mathrm{O}$ ) (Fiege et al. 1996; Kawamori et al. 1989; Nagashima and Mino 2013) or preferentially ${ }^{17} \mathrm{O}$ (nuclear spin $I=5 / 2$ ) in PS II samples with isotope-labeled $\mathrm{H}_{2}^{17} \mathrm{O}$ as the solvent (Lohmiller et al. 2017; McConnell et al. 2012; Rapatskiy et al. 2012). Methodological and instrumental developments in our laboratory (Cox et al. 2013a, 2017) allowed us to characterize the ${ }^{17} \mathrm{O}$ signals in the $\mathrm{S}_{2}$ and $\mathrm{S}_{0}$ states using electron-electron double resonance (ELDOR)-detected NMR (EDNMR) at high frequency (94 GHz) (Lohmiller et al. 2017; Rapatskiy et al. 2012), which yields significantly better sensitivity compared with ${ }^{17}$ O ENDOR (McConnell et al. 2012; Rapatskiy et al. 2012). Through spectral simulations, we could identify the $\mu$-oxo bridge $\mathrm{O} 5$ to be an exchangeable ligand in the $S_{2}$ state (Fig. 7A, B) (Lohmiller et al. 2014; Perez-Navarro et al. 2013; Rapatskiy et al. 2012). O5 represents the most probable candidate for the two-fold deprotonated substrate $\mathrm{W}_{\mathrm{s}}$ for the following reasons:

(i) It is the only exchangeable ${ }^{17} \mathrm{O}$ nucleus bound both to $\mathrm{Mn}$ and $\mathrm{Ca}$, a requirement imposed by MIMS experiments (Cox and Messinger 2013; Hendry and Wydrzynski 2003; Messinger 2004).

(ii) Shortening of an Mn-Mn bond observed by EXAFS has been explained by a deprotonation of an O-bridge and has been assigned to O5 (Robblee et al. 2002; Messinger 2004).

(iii) Similar timescales for the water exchange were found both for $\mathrm{W}_{\mathrm{s}}$ in the MIMS, see ref. (Hillier and Wydrzynski 2008), and for O5 in the EPR experiments, i.e., complete exchange in $<10$ s (Rapatskiy et al. 2012).

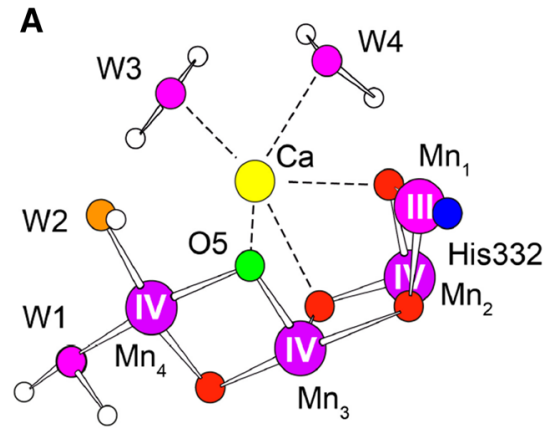

Fig. 7 A Mn cluster with the $\mu$-oxo bridges and bound $\mathrm{H}_{2} \mathrm{O} / \mathrm{OH}^{-}$ molecules in the $\mathrm{S}_{2}$ state; the same color code as in panel (B) is used. B ${ }^{17} \mathrm{O}$ EDNMR spectrum at W-band $(94 \mathrm{GHz})$ obtained from PS II core preparations (T. elongatus) in the $\mathrm{S}_{2}$ state. The buffer has been exchanged with $\mathrm{H}_{2}^{17} \mathrm{O}(90 \%$ enrichment) for $30 \mathrm{~min}(3 \times)$ in the dark $\left(S_{1}\right.$ state) prior to flash-advancement to the $S_{2}$ state (black trace). (iv) Orientation dependent EDNMR studies showed that the measured hyperfine coupling can only be assigned to O5 or O4) (Rapatskiy et al. 2012).

(v) Both $\mathrm{Ca} / \mathrm{Sr}$ exchange experiments and ammonia inhibition studies demonstrate $\mathrm{O} 5$ and only $\mathrm{O} 5$ to be an exchangeable oxygen bridge (Cox et al. 2011; PerezNavarro et al. 2013).

This is in agreement with earlier low frequency FTIR studies of the OEC that showed that a $\mu_{2}$-oxo or $\mu_{3}$-oxo bridge is exchangeable (Chu et al. 2000). It is remarkable that in the OEC a $\mu$-oxo bridge is readily exchangeable. For structurally similar model compounds an exchange has only been observed on much longer timescales (Rapatskiy et al. 2015; Tagore et al. 2006, 2007). These results further demonstrate the dynamic nature of this O5 ligand in the OEC (see above, Fig. 5).

Recent ${ }^{17} \mathrm{O}$ EDNMR investigations of $\mathrm{H}_{2}^{17} \mathrm{O}$ binding to the $S_{0}$ state of the OEC show that an $\mathrm{OH}^{-}$is introduced in the initial step of the cycle (the 1st substrate water that has lost a proton) after $\mathrm{O}_{2}$ release in the $S_{4}$ to $S_{0}$ transition (Lohmiller et al. 2017). In the $S_{0}$ and $S_{1}$ state the $\mathrm{O} 5$ is thought to exist in an open cubane-type structure (in $S_{0}$ with $S=1 / 2$, and in $S_{1}$ with $S=0$ ground state) as shown in Fig. 8 .

As described above, recent spectroscopic results, including high field EPR indicate that a new water molecule (O6) is inserted into the manganese cluster in the $S_{3}$ state as an $\mathrm{OH}^{-}$at the open coordination site of Mn1 (Cox et al. 2014). Its close proximity to $\mathrm{O} 5$ suggests it is the second substrate $W_{\mathrm{f}}$ (Fig. 6B). How it is exactly inserted remains an open question. Recent SFX data (Kern et al. 2018; Suga et al. 2017) indicate that the Glu189, which bridges the $\mathrm{Ca}^{2+}$ ion and $\mathrm{Mn} 1$ in the $S_{1}$ state detaches from the $\mathrm{Ca}^{2+}$ ion upon formation of the $S_{3}$ state. This removes steric hindrance to direct water binding via the $\mathrm{Ca}^{2+}$ channel, i.e., it is originally

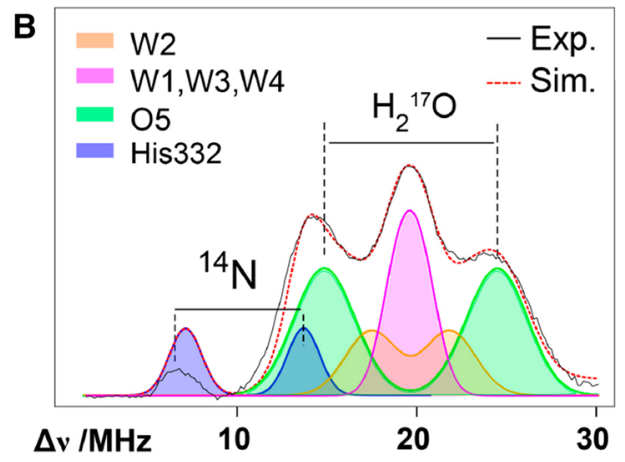

EDNMR spectra are also shown for $\mathrm{H}_{2}^{16} \mathrm{O}$ buffer, containing only ${ }^{14} \mathrm{~N}$ signals (dark blue trace, ${ }^{14} \mathrm{~N}$ from histidine His332, see Fig. 2C). Three classes of oxygen ligands were assigned: the largest ${ }^{17} \mathrm{O}$ splitting belongs to the exchangeable $\mu$-oxo bridge $\mathrm{O} 5$ (green), the smaller ones to the $\mathrm{H}_{2} \mathrm{O} / \mathrm{OH}^{-}$molecules (orange, purple) indicated in the figure. For further details see (Rapatskiy et al. 2012) 


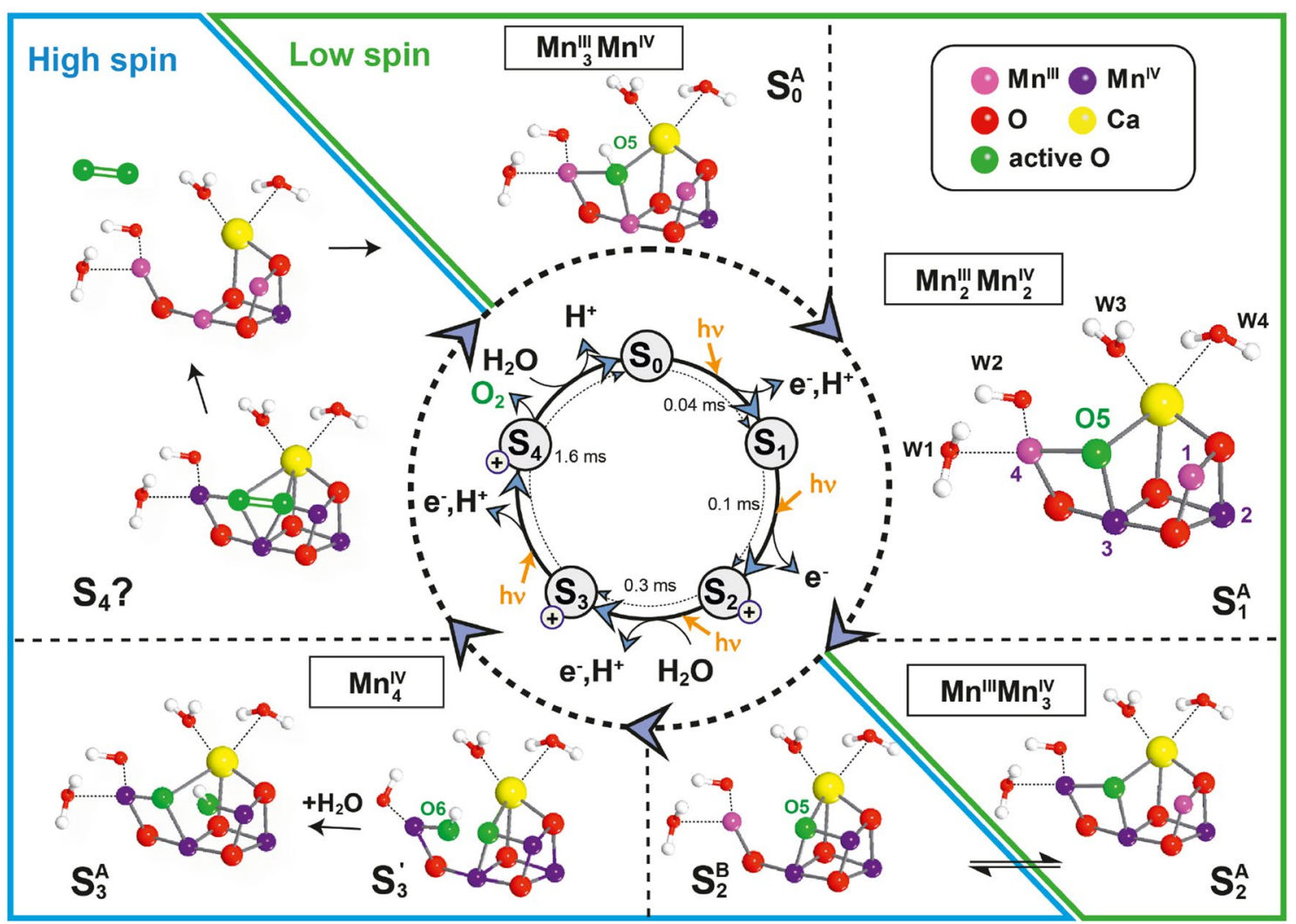

Fig. 8 Model for the water oxidation cycle in PS II based on spectroscopic and theoretical work (Cox et al. 2015; Krewald et al. 2016) detailing the structures of the Mn cluster in the different $S$ states, the water binding events and the $\mathrm{O}-\mathrm{O}$ bond formation and $\mathrm{O}_{2}$ release in $S_{4}$. The boxes show the determined oxidation states of the $\mathrm{Mn}$ ions in the respective $S$ state. A color code is used for the assignment of the $\mathrm{Mn}^{\mathrm{III}}$ (light purple) and $\mathrm{Mn}^{\mathrm{IV}}$ (dark purple) ions when the OEC is passing through the $S$ states. Note that the oxygens of the waters and $\mu$-oxo bridges are given in red except for the proposed substrate oxygens $\mathrm{O} 5$ and $\mathrm{O} 6$ (green). The $S_{2}$ state exists in two conformations (closed/open cubanes), see text. $S_{3}$ may also exist in an open $\left(S_{3}^{\mathrm{A}}\right)$ and a closed $\left(S_{3}^{\mathrm{B}}\right)$ cubane form (not shown). For $S_{3}$ a state $S_{3}{ }^{\prime}$ is shown in

one of the $\mathrm{Ca}^{2+}$ waters. Another possibility is that this $\mathrm{OH}^{-}(\mathrm{O} 6)$ is introduced in an indirect fashion by toggling between the open and closed cubane structures and is thus derived from $\mathrm{W} 2$, one of the terminal ligands of Mn4 (compare structure $S_{3}{ }^{\prime}$ in Fig. 8 ). Within this sequence the water that binds during the $S_{2}$ to $S_{3}$ transition is not one of the substrates of the current cycle, but a substrate of the next cycle (Cox and Messinger 2013). It also implies that O5 (the existing $\mu$-oxo bridge) and 06 (the new water-derived oxygen ligand) may switch identities. There is significant theoretical support for this sequence, which explains how redox tuning of the cofactor can precede water binding (Retegan et al. 2016). This hypothesis also better agrees with MIMS data which shows both substrates are bound to the cofactor (most likely to $\mathrm{Mn}$ ions) in all $S$-states and that the rate of exchange does not dramatically change upon moving from which manganese oxidation has occurred but the 2nd water has not been introduced. This state is present in native sample in a minority of PS II centers, but it is stabilized upon specific chemical treatment (methanol addition or $\mathrm{Ca}^{2+}$ to $\mathrm{Sr}^{2+}$ exchange) (Chrysina et al. 2019). A switching of the preferred total spin ground state configuration of the cluster is thought to take place in $S_{2}$ from low to high spin and between $S_{4}$ and $S_{0}$ back from high to low spin; this is indicated by the diagonal line dividing the green and blue boxes. This switching of the spin state may be necessary for the formation of triplet dioxygen ${ }^{3} \mathrm{O}_{2}$ in the final step of the cycle (see also Fig. 10). Figure changed from (Krewald et al. 2016)

$S_{2}$ to $S_{3}$ (Cox and Messinger 2013; Hendry and Wydrzynski 2002, 2004).

\section{The water oxidation cycle in PS II}

As a consequence of the above results, it is assumed in the following discussion of the catalytic cycle of the OEC that the $\mathrm{O} 5$ bridge derives from one of the substrate waters $\left(\mathrm{W}_{\mathrm{s}}\right)$. A possible cycle is shown in Fig. 8 (Cox et al. 2015; Krewald et al. 2016). The first water $\mathrm{W}_{\mathrm{s}}$ binds as an $\mathrm{OH}^{-}$(O5) in the $S_{0}$ state, being deprotonated during the subsequent oxidation step to $S_{1}$. In the $S_{3}$ state the second substrate water enters the reaction as $\mathrm{OH}^{-}$(O6) to $\mathrm{Mn} 4$ (or $\mathrm{Mn} 1$ ) as suggested by the results obtained from EPR and XFEL experiments on the $\mathrm{S}_{3}$ state (Cox et al. 2014; Kern et al. 2018; Suga et al. 
2017). A further oxidation and deprotonation step leads to $S_{4}$. Experimental evidence shows that formation of $S_{4}$ is triggered by proton release (Haumann et al. 2005a; Klauss et al. 2012a). Current theoretical models suggest that a proton is transferred from W1 $\left(\mathrm{H}_{2} \mathrm{O}\right)$ to Asp61, as in the preceding $S_{2}$ to $S_{3}$ transition (Siegbahn 2012). Mutants of PSII lacking Asp61 show a pH dependency of the lag phase during the $S_{3}-S_{0}$ transition which has been attributed to a deprotonation of the $\mathrm{Mn}_{4} \mathrm{CaO}_{5}$ (Bao and Burnap 2015; Dilbeck et al. 2012) in support of this model.

In the current literature, there are several proposed mechanisms that suggest the early onset of $\mathrm{O}-\mathrm{O}$ bond formation in the $S_{3}$ state (Corry and O'Malley 2018). This is mainly based on the SFX crystal structure of Suga et al. which modeled a short distance between the $\mathrm{O} 5$ and $\mathrm{O} 6$ bridges in the $S_{3}$ state (Suga et al. 2017). We note that the more recent higher resolution SFX structure of the $S_{3}$ state (Kern et al. 2018), does not exhibit this short O5-O6 distance, and is instead more consistent with the high field EPR structure described above. Furthermore, earlier biophysical measurements categorically rule out $\mathrm{O}-\mathrm{O}$ bond formation in the $S_{3}$ state. The MIMS data described above shows that both substrates still rapidly exchange with bulk water in the $S_{3}$ state (Messinger et al. 1995). It is only upon oxidation and proton release to form the $S_{3} Y_{\mathrm{z}}$ state directly preceding $S_{4}$ that substrate exchange is 'arrested' indicating the onset of $\mathrm{O}-\mathrm{O}$ bond formation, i.e., formation of a peroxo type intermediate (Nilsson et al. 2014).

How the $\mathrm{O}-\mathrm{O}$ bond is precisely formed in the $S_{4}$ state is still unknown, owing to a lack of experimental data. There are two popular chemical mechanisms for this transition that differ with regard to what component of the cofactor is oxidized to form $S_{4}$ : (i) a ligand (one of the substrate waters); or (ii) a metal (one of the Mn ions). In the case of a ligand oxidation event, forming a $\mathrm{Mn}^{\mathrm{IV}}$-oxyl moiety, $\mathrm{O}-\mathrm{O}$ bond formation is proposed to proceed by a radical coupling mechanism described below. In the case of a metal oxidation event, forming a $\mathrm{Mn}^{\mathrm{V}}$-oxo type moiety, $\mathrm{O}-\mathrm{O}$ bond formation is instead proposed to proceed by nucleophilic attack of the electrophilic oxygen (O5) bound to the $\mathrm{Mn}^{\mathrm{V}}$ by a nearby water, e.g., W3 bound to the $\mathrm{Ca}^{2+}$. Unfortunately the nature of the last oxidation (ligand vs. metal centered) does not resolve this question. XAS data which monitors an oxidation state change of the Mn ions during the $S_{3}$ to $S_{0}$ transition appears to rule out a $\mathrm{Mn}^{\mathrm{V}}$ intermediate (Haumann et al. 2005a), favoring instead a ligand (oxygen) oxidation. We note that while the nucleophilic attack mechanism initially envisaged the involvement of a $\mathrm{Mn}^{\mathrm{V}}$ intermediate, it was later suggested to have substantial $\mathrm{Mn}^{\mathrm{IV}}$ oxyl character in the $S_{4}$ state based on theoretical studies (Vinyard and Brudvig 2017).

Only a nucleophilic attack mechanism has been observed for first row molecular transition metal water oxidation catalysts, for which there is mechanistic data, (Codola et al. 2015) with radical coupling to be thus far only described for second row transition metals, e.g., ruthenium (Cox and Lubitz 2013; Romain et al. 2009). Nucleophilic attack mechanisms have thus been proposed for the OEC by a number of groups (Ferreira et al. 2004; Pecoraro et al. 1998); see (Barber 2017; Vinyard and Brudvig 2017; Vinyard et al. 2015) for recent reviews. In this sequence, a nearby water (e.g., W3) attacks a manganese bound oxygen, most likely O5. Upon re-reduction of the four Mn ion and loss of the product $\mathrm{O}_{2}$, the newly inserted $\mathrm{O} 6$ bridge presumably fills the site vacated by $\mathrm{O} 5$ leading to rapid recovery of the $S_{0}$ state.

In contrast the oxo-oxyl radical coupling mechanism involving two Mn bound oxygens, is most compatible with the assignment of the two substrates sites described in the previous section (O5 and O6). Such a mechanism was first proposed ten years ago by Per Siegbahn (Siegbahn 2009). Importantly high field $S_{3}$ state EPR data has demonstrated that there is the requisite spin alignment of the two putative substrate oxygens and the Mn ions to which they are bound $(\mathrm{Mn} 4-\mathrm{O} 5-\mathrm{O} 6-\mathrm{Mn} 1=\beta \alpha \beta \alpha)$ on which this mechanism is based.

To illustrate the current situation, in Fig. 9 three different structures are shown preceding the $\mathrm{O}-\mathrm{O}$ bond formation in $S_{4}$. They are derived from the $S_{3}$ open and closed cubane structures, $S_{3}^{\mathrm{A}}$ and $S_{3}^{\mathrm{B}}$, and from $S_{3}{ }^{\prime}$ in which a second water has not (yet) been bound (Fig. 8). In panel (A) and
A

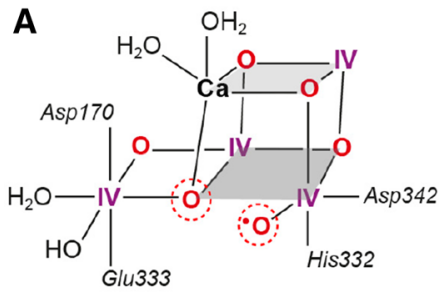

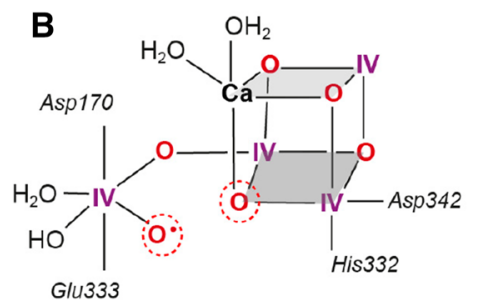

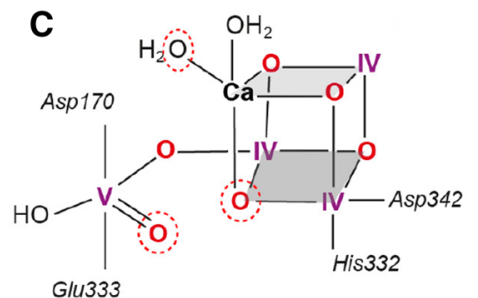

Fig. 9 Three representative model structures for the final step in the Kok cycle with O5 and O6 bound (see Figs. 8, 10); A Mn(IV)-oxyl formation at Mn1, octahedral coordination, all Mn(IV), open cubane structure; B Mn(IV)-oxyl formation at Mn4, octahedral, closed cubane structure; $\mathbf{C ~} \mathrm{Mn}(\mathrm{V})=\mathrm{O}$ formation at $\mathrm{Mn} 4$, trigonal bipyramidal, closed cubane. The putative reacting oxygens are indicated by dotted red circles; for details see text. Figure adopted from (Pantazis 2018) 
(B) the open and closed cubane structures are shown with all $\mathrm{Mn}(\mathrm{IV})$ and $\mathrm{O} 5$ and $\mathrm{O} 6$ in close contact that could react to form dioxygen via an oxyl-oxo coupling mechanism. In panel C) the dangling Mn4 is 5-coordinate; in the shown geometry the formation of a $\mathrm{Mn}(\mathrm{V})=\mathrm{O}$ species is preferred in which the electrophilic oxygen could be attacked by a nucleophilic water (e.g., bound to $\mathrm{Ca}$ ) or a neighboring oxo group as pointed out by Pantazis (2018). In this context it should be mentioned that in the recent SFX structure (Kern et al. 2018) only the open cubane structure has been observed for $S_{2}$ and $S_{3}$ which led the authors to propose O5 to react with either O6 (here called Ox) bound to Mn1 or with W3 (at Ca) or W2 (at Mn4).

There are also other alternative mechanisms. A very recent example, proposed by the Yamaguchi group, involves an $\mathrm{O}-\mathrm{O}^{*}$ radical intermediate, formed following electron transfer to $Y_{\mathrm{Z}}$ (Shoji et al. 2018). Similarly, there are proposed mechanisms that do not fall into either of the two categories, such as a recent proposal from the Sun group. In this novel mechanism, the dangler Mn acts as the site of catalysis, as in a nucleophilic attack like mechanism, forming a $\mathrm{Mn}^{\mathrm{VII}}$-dioxo intermediate following charge rearrangement of the Mn cluster in the $S_{4}$ state (Zhang and Sun 2018). As above for the nucleophilic attack mechanism, it is unclear if this mechanism is compatible with XAS data (Haumann et al. 2005a). For a more detailed comparison of alternative mechanisms the reader is directed to a recent in-depth review (Pantazis 2018).

Owing to the increasing experimental support for the oxooxyl coupling mechanism first proposed by Siegbahn, a brief description of its key steps is given below (Fig. 10). The first stage of the mechanism involves oxidation of O6 to form an oxyl radical, in concert with deprotonation. In the Siegbahn mechanism, the proton associated with $\mathrm{O} 6$ in $S_{3}$ migrates to $\mathrm{W} 1$, which is already deprotonated during $S_{3}$ formation. The generated oxyl radical carries an unpaired $\beta$ spin electron, because 06 is antiferromagnetically coupled to Mn1. The oxyl radical then attacks the $\mathrm{O} 5$ bridge which carries a small excess of $\alpha$ spin. This results in formation of an $\sigma \mathrm{O}-\mathrm{O}$ bond between $\mathrm{O} 5$ and $\mathrm{O} 6$ - with the new $\sigma$ bond consisting of the $\alpha$ spin electron of $\mathrm{O} 5$ and the $\beta$ spin electron of $\mathrm{O}_{6}$ (Fig. 10 $\left[S_{4}\right.$ oxyl]). The $\alpha$ spin electron comes from the cleavage of the existing $\mathrm{Mn}-\mathrm{O}$ bond between $\mathrm{O} 5$ and $\mathrm{Mn} 4$. The $\beta$ spin electron of the cleaved $\mathrm{Mn}-\mathrm{O}$ bond is transferred back to $\mathrm{Mn} 4$, reducing its oxidation state to III+. Note that the $\beta$ electron of the cleaved $\mathrm{Mn}-\mathrm{O}$ bond has the same spin as the three existing d-electrons of Mn4, and thus this transfer can occur without energy penalty due to spin conversion.

Subsequently, a peroxo product (a bound $\mathrm{O}_{2}$ with a single $\sigma$ bond) is formed bridging Mn3 and Mn1 (Fig. 10 [ $\mathrm{S}_{4}$ peroxo]). Mn4 is now five coordinate with the product peroxide sitting along its Jahn-Teller (JT) axis (Li and Siegbahn 2015; Siegbahn 2009). Cleavage of the two remaining $\mathrm{Mn}-\mathrm{O}$ bonds leads to formation of the final $\mathrm{O}_{2}$ product. Importantly the cleavage of each $\mathrm{Mn}-\mathrm{O}$ bond results in an $\alpha$ spin electron being transferred to each of the two Mn ions that were attached to the peroxide and a $\beta$ spin electron being transferred to $\mathrm{O} 5$ and $\mathrm{O6}$. As before, this is an energetically favorable situation as the electron gained by each metal is of the same spin $(\alpha)$ as their existing $d$-electrons. The two new

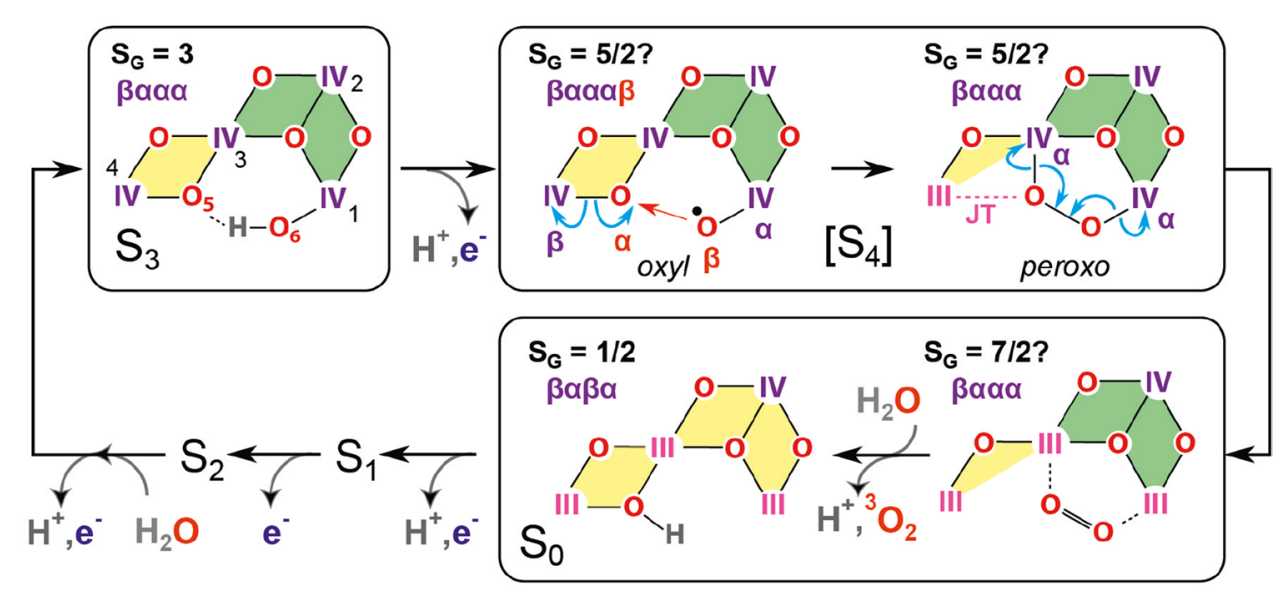

Fig. 10 Spin alignment in the $S_{3},\left[S_{4}\right]$ and $S_{0}$ states that fosters low barrier $\mathrm{O}-\mathrm{O}$ bond formation as described by Siegbahn (Siegbahn 2009). $S_{3}$ and $S_{0}$ have been characterized experimentally; [ $\left.S_{4}\right]$ has not been observed. The spin ground state $S_{\mathrm{G}}$ is indicated. The numbering of the Mn ions (1-4) is given for the $S_{3}$ state; the oxidation state of each $\mathrm{Mn}$ ion is given in light purple (III) or dark purple (IV); antiferromagnetic interaction between adjacent $\mathrm{Mn}$ ions is represented by yellow shading whereas ferromagnetic interaction by green shading.
The spin alignment of the $\mathrm{Mn}$ ions in each state is given on the top (the order is: Mn4-Mn3-Mn2-Mn1); the spin of the oxyl radical at the $\left[S_{4}\right.$ oxyl $]$ state is indicated by the red colored $\beta$. The Jahn-Teller (JT) axis of the $\mathrm{Mn}^{\mathrm{III}}$ of the $\left[S_{4}\right.$ peroxo] intermediate is depicted by a dashed purple line. Evidence of the spin alignment of Mn4-O5O6-Mn1 in the $\left[S_{4}\right.$ oxyl] state $(\beta \alpha \beta \alpha)$ is derived from experiments on the $S_{3}$ state (Cox et al. 2014; Krewald et al. 2016). For details of the mechanism see text 
$\beta$ spin electrons occupy two $\pi^{*}$ orbitals giving rise to the triplet $\mathrm{O}_{2}$ product. The displacement of $\mathrm{O}_{2}$, via binding of the first substrate water of the next $\mathrm{S}$ cycle (coupled to its deprotonation), leads to formation of the observed (metastable) $S_{0}$ state (Fig. 10, $S_{0}$ ). The $\mathrm{O}_{2}$ may detach in a stepwise fashion, during its concerted replacement with $\mathrm{OH}^{-}$, passing through a transient superoxo intermediate ( $\mathrm{Li}$ and Siegbahn 2015).

New experimental data is needed to probe these key stages in $\mathrm{O}-\mathrm{O}$ bond formation and release. SFX crystallography (Kern et al. 2014, 2018; Kupitz et al. 2014; Suga et al. 2015, 2017; Young et al. 2016) is poised to address structural changes during the $S_{3}$ to $S_{0}$ transition, and may suggest an alternative proton transfer sequence. Specifically, as described above, the Siegbahn mechanism starts with internal proton transfer from $\mathrm{O} 6$ to $\mathrm{W} 1$. We note, however, that recent SFX measurements indicate that Glu189 detaches from the $\mathrm{Ca}^{2+}$ ion during S-state progression. Glu189 is proximal to $\mathrm{Mn} 1$ and could act as an internal base, accepting a proton from $\mathrm{O}_{6}$, similar to old ideas put forward by Gerry Babcock (Hoganson and Babcock 1997). Within this revised scheme $\mathrm{W} 1$ does not need to undergo deprotonation-with proton transfer to Asp61 switched off due to a conformational change (gating) (Kern et al. 2018).

\section{Conclusions}

In biology, there is only one catalytic site that is able to split water-the OEC - and its structure and function is identical (Su et al. 2011) in cyanobacteria, algae and all higher plants; however, differences in the second coordination sphere between higher plants and cyanobacteria have been reported (Retegan and Pantazis 2017). Many other enzymes have found different ways to perform their task-but not the unique, highly optimized OEC in PS II. The work compiled above shows that this unique metal cluster requires the presence and concerted action of all four manganese ions in the $\mathrm{Mn}_{4} \mathrm{O}_{\mathrm{x}} \mathrm{Ca}$ complex. The oxidation states of the $\mathrm{Mn}$ ions are always III or IV-there exists no $\mathrm{Mn}^{\mathrm{II}}$ in the whole cycle. The possible presence of a $\mathrm{Mn}^{\mathrm{V}}$ in the last step $\left(\mathrm{S}_{4}\right)$ has, however, not yet been finally clarified. The importance of the total electron spin state of the cluster has been highlightedand is understandable considering the necessary restriction to form and release triplet dioxygen ${ }^{3} \mathrm{O}_{2}$. The $\mathrm{Ca}^{2+}$ is probably important for efficient water delivery and the $\mathrm{Cl}^{-}$for maintaining the correct charge balance of the OEC. Water delivery is optimized through highly efficient water channels leading to the Mn cluster. In the favored model the two substrate waters bind to neighboring redox-active Mn ions, and deprotonation of these waters is coupled to the oxidation events of the cluster. Close proximity and proper alignment of the two active oxygens are assured to efficiently form the
$\mathrm{O}-\mathrm{O}$ bond and finally release the ${ }^{3} \mathrm{O}_{2}$ molecule with high efficiency.

In spite of the great progress in the understanding of the OEC in PS II there are still several challenges to be tackled. One pertinent open question is the structure of the elusive $\mathrm{S}_{4}$ state. A possible stabilization and characterization of this state would finally complete our knowledge of the $\mathrm{S}$ states of the Kok cycle. A missing key experiment is further the detection of the 6th oxygen in the manganese cluster by EPR (using ${ }^{17} \mathrm{O}$ labeling) to support the recent crystallographic XFEL (SFX) data on the $S_{3}$ state (Kern et al. 2018; Suga et al. 2017). Furthermore the determination of the water binding kinetics should be followed for all state transitions by rapid freeze quench (RFQ) techniques combined with advanced EPR techniques. First experiments along these lines have successfully been performed in our laboratory using time resolved RFQ ${ }^{17} \mathrm{O}$ EDNMR measurements (Rapatskiy et al., unpublished data). The exchange of certain amino acids in the vicinity of the OEC could shed light on the fine-tuning of its electronic structure in the $\mathrm{S}$ state cycle and would be important for explaining its high turnover frequency. Furthermore, a great challenge for chemists working in the field of water oxidation is the understanding and modeling of the sophisticated mechanism by which PS II repairs photo-damage of its protein, of the pigments and of the manganese cluster.

The properties of the OEC in PS II described above represent valuable design features for bioinspired light-driven molecular catalysts for water oxidation. The following points are considered essential for such catalysts:

1. The material of the catalyst must be abundant, easily accessible, inexpensive (i.e., no precious metals), nontoxic, sufficiently stable under working conditions and should be scalable.

2. The required four oxidizing equivalents must be stored in the catalyst to couple the fast 1-electron photochemical reaction with the slow 4-electron chemical water oxidation process.

3. The binding of the two substrate water molecules should preferentially take place at two well-defined neighboring redox-active metal centers, accompanied by successive deprotonation and activation of the water molecules.

4. The redox steps of the catalytic metal centers should be of similar magnitude and in the range of $1 \mathrm{eV}$, and should finally lead to a concerted water oxidation, $\mathrm{O}_{2}$ formation and $\mathrm{O}_{2}$ release, to avoid reactive oxygen intermediates. This also requires a sequential release of the 4 protons.

5. A functional matrix mimicking the protein (in PS II) is needed for efficient transport of water to the reaction zone, release of dioxygen and for the correct proton management. 
6. In the photochemical act, a light-induced species must be generated with sufficient oxidative power to oxidize water $(+1.23 \mathrm{eV})$.

7. Effective coupling of the charge separation unit with the catalytic center (metal cluster) is necessary to diminish the overpotential (comparable to the function of the tyrosine $Y_{\mathrm{Z}}$ in PS II).

8. The catalytic unit should be stable; in case of deterioration/destruction a mechanism of self-repair or healing should be in place to avoid deactivation of the catalytic process.

At present, it is still a great challenge to create a catalyst that fulfills the above criteria and could thus compete with the Mn cluster in PS II. The future will show if at least part of the above points can be fulfilled. Attempts to synthesize water splitting chemical catalysts and devices are too numerous in the literature to be discussed here-but show the great importance of this research field for a future society using (only) renewable, sustainable energy based on sunlight driven processes (Andreiadis et al. 2011; Blakemore et al. 2015; Kanan and Nocera 2008; Kurz 2016; Najafpour et al. 2016; Tran et al. 2012; Zhang et al. 2015; Matheu et al. 2019).

Acknowledgements Open access funding provided by Max Planck Society. Financial support of this work by the Max Planck Society and MANGAN (03EK3545) funded by the Bundesministeriums für Bildung und Forschung is gratefully acknowledged. N.C. acknowledges the support of the Australian Research Council (FT140100834).

\section{Compliance with ethical standards}

Conflict of interest The authors declare that they have no conflict of interest.

Open Access This article is distributed under the terms of the Creative Commons Attribution 4.0 International License (http://creativeco mmons.org/licenses/by/4.0/), which permits unrestricted use, distribution, and reproduction in any medium, provided you give appropriate credit to the original author(s) and the source, provide a link to the Creative Commons license, and indicate if changes were made.

\section{References}

acatech-National Academy of Science and Engineering, Leopoldina-German National Academy of Sciences, Union of the German Academies of Sciences and Humanities (ed) (2018) Artificial photosynthesis. National Academy of Science and Engineering, Munich

Ahrling KA, Peterson S, Styring S (1997) An oscillating manganese electron paramagnetic resonance signal from the $S_{0}$ state of the oxygen evolving complex in photosystem II. Biochemistry $36: 13148-13152$
Ames W, Pantazis DA, Krewald V, Cox N, Messinger J, Lubitz W, Neese F (2011) Theoretical evaluation of structural models of the $\mathrm{S}_{2}$ state in the oxygen evolving complex of photosystem II: protonation states and magnetic interactions. J Am Chem Soc 133:19743-19757

Andreiadis ES, Chavarot-Kerlidou M, Fontecave M, Artero V (2011) Artificial photosynthesis: from molecular catalysts for lightdriven water splitting to photoelectrochemical cells. Photochem Photobiol 87:946-964

Babcock GT, Blankenship RE, Sauer K (1976) Reaction-kinetics for positive charge accumulation on water side of chloroplast photosystem 2. FEBS Lett 61:286-289

Bao H, Burnap RL (2015) Structural rearrangements preceding dioxygen formation by the water oxidation complex of photosystem II. Proc Natl Acad Sci USA 112:6139-6147

Barber J (2017) A mechanism for water splitting and oxygen production in photosynthesis. Nat Plants 3:17041

Beck WF, Depaula JC, Brudvig GW (1986) Ammonia binds to the manganese site of the $\mathrm{O}_{2}$-evolving complex of photosystem-II in the $\mathrm{S}_{2}$ state. J Am Chem Soc 108:4018-4022

Bekker A, Holland HD, Wang PL, Rumble D, Stein HJ, Hannah JL, Coetzee LL, Beukes NJ (2004) Dating the rise of atmospheric oxygen. Nature 427:117-120

Bencini A, Gatteschi D (1990) Electron paramagnetic resonance of exchange coupled systems. Springer, New York

Berthomieu C, Hienerwadel R, Boussac A, Breton J, Diner BA (1998) Hydrogen bonding of redox-active tyrosine $\mathrm{Z}$ of photosystem II probed by FTIR difference spectroscopy. Biochemistry 37:10547-10554

Blakemore JD, Crabtree RH, Brudvig GW (2015) Molecular catalysts for water oxidation. Chem Rev 115:12974-13005

Blankenship RE et al (2011) Comparing photosynthetic and photovoltaic efficiencies and recognizing the potential for improvement. Science 332:805-809

Blankenship RE (ed) (2014) Molecular mechanisms of photosynthesis, 2nd edn. Wiley-Blackwell, Chichester

Bondar AN, Dau H (2012) Extended protein/water H-bond networks in photosynthetic water oxidation. Biochim Biophys Acta 1817:1177-1190

Boussac A, Rutherford AW (1988) Nature of the inhibition of the oxygen-evolving enzyme of photosystem-II induced by $\mathrm{NaCl}$ washing and reversed by the addition of $\mathrm{Ca}^{2+}$ or $\mathrm{Sr}^{2+}$. Biochemistry 27:3476-3483

Boussac A, Zimmermann JL, Rutherford AW (1989) Epr signals from modified charge accumulation states of the oxygen evolving enzyme in $\mathrm{Ca}^{2+}$ deficient photosystem II. Biochemistry 28:8984-8989

Boussac A, Zimmermann JL, Rutherford AW (1990) Further characterization of the modified $\mathrm{S}_{2}$ and $\mathrm{S}_{3}$ Epr signals observed in $\mathrm{Ca}^{2+}$ depleted photosystem-II reconstituted with the 17 and $23 \mathrm{kDa}$ polypeptides. Curr Res Photosynth 1-4:713-716

Boussac A, Girerd JJ, Rutherford AW (1996) Conversion of the spin state of the manganese complex in photosystem II induced by near-infrared light. Biochemistry 35:6984-6989

Boussac A, Sugiura M, Lai TL, Rutherford AW (2008) Low-temperature photochemistry in photosystem II from Thermosynechococcus elongatus induced by visible and near-infrared light. Philos Trans R Soc B 363:1203-1210

Boussac A, Sugiura M, Rutherford AW, Dorlet P (2009) Complete EPR spectrum of the $S_{3}$ state of the oxygen-evolving photosystem II. J Am Chem Soc 131:5050-5051

Boussac A, Rutherford AW, Sugiura M (2015) Electron transfer pathways from the $\mathrm{S}_{2}$ states to the $\mathrm{S}_{3}$ states either after a $\mathrm{Ca}^{2+}$ / $\mathrm{Sr}^{2+}$ or a Cl${ }^{-} / \mathrm{I}^{-}$exchange in photosystem II from Thermosynechococcus elongatus. Biochim Biophys Acta 1847:576-586 
Bovi D, Narzi D, Guidoni L (2013) The $\mathrm{S}_{2}$ state of the oxygen evolving complex of photosystem II explored by QM/MM dynamics: Spin surfaces and metastable states suggest a reaction path towards the $\mathrm{S}_{3}$ state. Angew Chem 52:11744-11749

Brettel K, Schlodder E, Witt HT (1984) Nanosecond reduction kinetics of photooxidized chlorophyll-alpha-II (P680) in single flashes as a probe for the electron pathway, $\mathrm{H}^{+}$release and charge accumulation in the $\mathrm{O}_{2}$ evolving complex. Biochim Biophys Acta 766:403-415

Britt RD, Zimmermann JL, Sauer K, Klein MP (1989) Ammonia binds to the catalytic Mn of the oxygen-evolving complex of photosystem-II: evidence by electron-spin echo envelope modulation spectroscopy. J Am Chem Soc 111:3522-3532

Britt RD, Peloquin JM, Campbell KA (2000) Pulsed and parallelpolarization EPR characterization of the photosystem II oxygen-evolving complex. Annu Rev Biophys Biomed 29:463-495

Britt RD et al (2004) Recent pulsed EPR studies of the photosystem II oxygen-evolving complex: implications as to water oxidation mechanisms. Biochim Biophys Acta 1655:158-171

Calvin M (1962) Path of carbon in photosynthesis. Science 135:879-889

Cardona T, Sedoud A, Cox N, Rutherford AW (2012) Charge separation in photosystem II: a comparative and evolutionary overview. Biochim Biophys Acta 1817:26-43

Casey JL, Sauer K (1984) Electron-paramagnetic-res detection of a cryogenically photogenerated intermediate in photosynthetic oxygen evolution. Biochim Biophys Acta 767:21-28

Chabi S, Papadantonakis KM, Lewis NS, Freund MS (2017) Membranes for artificial photosynthesis. Energy Environ Sci 10:1320-1338

Chatterjee R et al (2016) Structural changes correlated with magnetic spin state isomorphism in the $\mathrm{S}_{2}$ state of the $\mathrm{Mn}_{4} \mathrm{CaO}_{5}$ cluster in the oxygen-evolving complex of photosystem II. Chem Sci 7:5236-5248

Chatterjee R et al (2019) Structural isomers of the S2 state in photosystem II: do they exist at room temperature and are they important for function? Physiol Plant 166:60-72

Chen H, Dismukes GC, Case DA (2018) Resolving ambiguous protonation and oxidation states in the oxygen evolving complex of photosystem II. J Phys Chem B 122:8654-8664

Chrysina $M$ et al (2019) New intermediates in the activation of nature's water splitting cofactor. Proc Natl Acad Sci USA, Under Revision

Chu HA, Nguyen AP, Debus RJ (1995) Amino acid residues that influence the binding of manganese or calcium to photosystemII. The lumenal interhelical domains of the D1 polypeptide. Biochemistry 34:5839-5858

Chu HA, Sackett H, Babcock GT (2000) Identification of a Mn-OMn cluster vibrational mode of the oxygen-evolving complex in photosystem II by low-frequency FTIR spectroscopy. Biochemistry 39:14371-14376

Codola Z, Gomez L, Kleespies ST, Que L, Costas M, Lloret-Fillol $\mathrm{J}$ (2015) Evidence for an oxygen evolving iron-oxo-cerium intermediate in iron-catalysed water oxidation. Nat Commun 6:5865. https://doi.org/10.1038/ncomms6865

Collings AF, Critchley C (2005) Artificial photosynthesis: from basic biology to industrial application. Wiley-VCH Weinheim, Chichester

Corry TA, O'Malley PJ (2018) Evidence of O-O bond formation in the final metastable $S_{3}$ state of nature's water oxidizing complex implying a novel mechanism of water oxidation. J Phys Chem Lett 9:6269-6274

Cox N, Lubitz W (2013) Molecular concepts of water splitting: nature's approach. In: Schlögl R (ed) Chemical energy storage. De Gruyter GmbH, Berlin/Boston, pp 185-224
Cox N, Messinger J (2013) Reflections on substrate water and dioxygen formation. Biochim Biophys Acta 1827:1020-1030

Cox $\mathrm{N}$ et al (2011) Effect of $\mathrm{Ca}^{2+} / \mathrm{Sr}^{2+}$ substitution on the electronic structure of the oxygen-evolving complex of photosystem II: a combined multifrequency EPR, ${ }^{55} \mathrm{Mn}$-ENDOR, and DFT study of the $S_{2}$ state. J Am Chem Soc 133:3635-3648

Cox N, Lubitz W, Savitsky A (2013a) W-band ELDOR-detected NMR (EDNMR) spectroscopy as a versatile technique for the characterisation of transition metal-ligand interactions. Mol Phys 111:2788-2808

Cox N, Pantazis DA, Neese F, Lubitz W (2013b) Biological water oxidation. Acc Chem Res 46:1588-1596

Cox N, Retegan M, Neese F, Pantazis DA, Boussac A, Lubitz W (2014) Electronic structure of the oxygen-evolving complex in photosystem II prior to O-O bond formation. Science 345:804-808

Cox N, Pantazis DA, Neese F, Lubitz W (2015) Artificial photosynthesis: understanding water splitting in nature. Interface Focus 5:20150009

Cox N, Nalepa A, Lubitz W, Savitsky A (2017) ELDOR-detected NMR: a general and robust method for electron-nuclear hyperfine spectroscopy? J Magn Reson 280:63-78

Croce R, van Amerongen H (2014) Natural strategies for photosynthetic light harvesting. Nat Chem Biol 10:492-501

Damoder R, Klimov VV, Dismukes GC (1986) The Effect of $\mathrm{Cl}^{-}$depletion and $\mathrm{X}^{-}$reconstitution on the oxygen-evolution rate, the yield of the multiline manganese electron-paramagnetic-res signal and electron-paramagnetic-res signal II in the isolated photosystem II complex. Biochim Biophys Acta 848:378-391

Dau H, Haumann M (2007) Eight steps preceding O-O bond formation in oxygenic photo synthesis: a basic reaction cycle of the photosystem II manganese complex. Biochim Biophys Acta $1767: 472-483$

Dau H, Haumann M (2008) The manganese complex of photosystem II in its reaction cycle - basic framework and possible realization at the atomic level. Coord Chem Rev 252:273-295

Debus RJ (2014) Evidence from FTIR difference spectroscopy that D1-Asp61 influences the water reactions of the oxygen-evolving $\mathrm{Mn}_{4} \mathrm{CaO}_{5}$ cluster of Photosystem II. Biochemistry 53:2941-2955

Debus RJ (2015) FTIR studies of metal ligands, networks of hydrogen bonds, and water molecules near the active site $\mathrm{Mn}_{4} \mathrm{CaO}_{5}$ cluster in photosystem II. Biochim Biophys Acta 1847:19-34

Deisenhofer J, Epp O, Miki K, Huber R, Michel H (1985) Structure of the protein subunits in the photosynthetic reaction center of $R h o$ dopseudomonas viridis at $3 \AA$ resolution. Nature 318:618-624

Dekker JP, Plijter JJ, Ouwehand L, Vangorkom HJ (1984a) Kinetics of manganese redox transitions in the oxygen-evolving apparatus of photosynthesis. Biochim Biophys Acta 767:176-179

Dekker JP, Van Gorkom HJ, Wensink J, Ouwehand L (1984b) Absorbance difference spectra of the successive redox states of the oxygen-evolving apparatus of photosynthesis. Biochim Biophys Acta 767:1-9

Dilbeck PL, Hwang HJ, Zaharieva I, Gerencser L, Dau H, Burnap RL (2012) The D1-D61 N mutation in Synechocystis sp. PCC 6803 allows the observation of $\mathrm{pH}$-sensitive intermediates in the formation and release of $\mathrm{O}_{2}$ from photosystem II. Biochemistry 51:1079-1091

Dismukes GC, Siderer Y (1981) Intermediates of a polynuclear manganese center involved in photosynthetic oxidation of water. Proc Natl Acad Sci USA 78:274-278

Faunce TA et al (2013) Energy and environment policy case for a global project on artificial photosynthesis. Energy Environ Sci 6:695-698

Ferreira KN, Iverson TM, Maghlaoui K, Barber J, Iwata S (2004) Architecture of the photosynthetic oxygen-evolving center. Science 303:1831-1838 
Fiege R, Zweygart W, Bittl R, Adir N, Renger G, Lubitz W (1996) EPR and ENDOR studies of the water oxidizing complex of photosystem II. Photosynth Res 48:227-237

Fischer WW, Hemp J, Johnson JE (2016) Evolution of oxygenic photosynthesis. Annu Rev Earth Plant Sci 44:647-683

Gabdulkhakov A, Guskov A, Broser M, Kern J, Muh F, Saenger W, Zouni A (2009) Probing the accessibility of the $\mathrm{Mn}_{4} \mathrm{Ca}$ cluster in photosystem II: channels calculation, noble gas derivatization, and cocrystallization with DMSO. Structure 17:1223-1234

Galstyan A, Robertazzi A, Knapp EW (2012) Oxygen-evolving Mn cluster in photosystem II: the protonation pattern and oxidation state in the high-resolution crystal structure. J Am Chem Soc 134:7442-7449

Goldfarb D, Stoll S (eds) (2018) EPR spectroscopy: fundamentals and methods. eMagRes Books and Wiley, New York

Gratzel M (2005) Solar energy conversion by dye-sensitized photovoltaic cells. Inorg Chem 44:6841-6851

Groot ML, Pawlowicz NP, van Wilderen LJGW, Breton J, van Stokkum IHM, van Grondelle R (2005) Initial electron donor and acceptor in isolated photosystem II reaction centers identified with femtosecond mid-IR spectroscopy. Proc Natl Acad Sci USA 102:13087-13092

Haddy A (2007) EPR spectroscopy of the manganese cluster of photosystem II. Photosynth Res 92:357-368

Haddy A, Lakshmi KV, Brudvig GW, Frank HA (2004) Q-band EPR of the $\mathrm{S}_{2}$ state of Photosystem II confirms an $\mathrm{S}=5 / 2$ origin of the $\mathrm{X}$-band $\mathrm{g}=4.1$ signal. Biophys J 87:2885-2896

Hamilton TL, Bryant DA, Macalady JL (2016) The role of biology in planetary evolution: cyanobacterial primary production in lowoxygen proterozoic oceans. Environ Microbiol 18:325-340

Hasegawa K, Kusunoki M, Inoue Y, Ono TA (1998) Simulation of $\mathrm{S}_{2}$ state multiline EPR signal in oriented photosystem II membranes: structural implications for the manganese cluster in an oxygen-evolving complex. Biochemistry 37:9457-9465

Hasegawa K, Ono TA, Inoue Y, Kusunoki M (1999) Spin-exchange interactions in the $\mathrm{S}_{2}$ state manganese tetramer in photosynthetic oxygen-evolving complex deduced from $\mathrm{g}=2$ multiline EPR signal. Chem Phys Lett 300:9-19

Haumann M, Liebisch P, Müller C, Barra M, Grabolle M, Dau H (2005a) Photosynthetic $\mathrm{O}_{2}$ formation tracked by time-resolved X-ray experiments. Science 310:1019-1021

Haumann M et al (2005b) Structural and oxidation state changes of the photosystem II manganese complex in four transitions of the water oxidation cycle $(\mathrm{S} 0 \rightarrow \mathrm{S} 1, \mathrm{~S} 1 \rightarrow \mathrm{S} 2, \mathrm{~S} 2 \rightarrow \mathrm{S} 3$, and $\mathrm{S} 3$, $\mathrm{S} 4 \rightarrow \mathrm{S} 0$ ) characterized by X-ray absorption spectroscopy at $20 \mathrm{~K}$ and room temperature. Biochemistry 44:1894-1908

Havelius KGV, Sjoholm J, Ho FM, Mamedov F, Styring S (2010) Metalloradical EPR signals from the $\mathrm{Y}_{\mathrm{Z}} \mathrm{S}$-state intermediates in photosystem II. Appl Magn Reson 37:151-176

Hendry G, Wydrzynski T (2002) The two substrate-water molecules are already bound to the oxygen-evolving complex in the $\mathrm{S}_{2}$ state of photosystem II. Biochemistry 41:13328-13334

Hendry G, Wydrzynski T (2003) O-18 isotope exchange measurements reveal that calcium is involved in the binding of one substratewater molecule to the oxygen-evolving complex in photosystem II. Biochemistry 42:6209-6217

Hillier W, Wydrzynski T (2000) The affinities for the two substrate water binding sites in the $\mathrm{O}_{2}$ evolving complex of photosystem II vary independently during S-state turnover. Biochemistry 39:4399-4405

Hillier W, Wydrzynski T (2004) Substrate water interactions within the photosystem II oxygen evolving complex. Phys Chem Chem Phys 6:4882-4889

Hillier W, Wydrzynski T (2008) O-18 water exchange in photosystem II: Substrate binding and intermediates of the water splitting cycle. Coord Chem Rev 252:306-317
Hillier W, Messinger J, Wydrzynski T (1998) Kinetic determination of the fast exchanging substrate water molecule in the $\mathrm{S}_{3}$ state of photosystem II. Biochemistry 37:16908-16914

Ho FM, Styring S (2008) Access channels and methanol binding site to the $\mathrm{CaMn}_{4}$ cluster in photosystem II based on solvent accessibility simulations, with implications for substrate water access. Biochim Biophys Acta 1777:140-153

Hoganson CW, Babcock GT (1997) A metalloradical mechanism for the generation of oxygen from water in photosynthesis. Science 277:1953-1956

Holland HD (2006) The oxygenation of the atmosphere and oceans. Philos Trans R Soc B 361:903-915

Holzwarth AR, Muller MG, Reus M, Nowaczyk M, Sander J, Rogner M (2006) Kinetics and mechanism of electron transfer in intact photosystem II and in the isolated reaction center: pheophytin is the primary electron acceptor. Proc Natl Acad Sci USA 103:6895-6900

Isobe $\mathrm{H}$ et al (2012) Theoretical illumination of water-inserted structures of the $\mathrm{CaMn}_{4} \mathrm{O}_{5}$ cluster in the $\mathrm{S}_{2}$ and $\mathrm{S}_{3}$ states of oxygen-evolving complex of photosystem II: full geometry optimizations by B3LYP hybrid density functional. Dalton Trans 41:13727-13740

Joliot P, Barbieri G, Chabaud R (1969) A new model of photochemical centers in system 2. Photochem Photobiol 10:309-329

Junge W (2019) Oxygenic photosynthesis: history, status and perspective. Q Rev Biophys 52:1-17

Junge W, Nelson N (2015) ATP synthase. Annu Rev Biochem 84:631-657

Kamiya N, Shen JR (2003) Crystal structure of oxygen-evolving photosystem II from Thermosynechococcus vulcanus at 3.7 A resolution. Proc Natl Acad Sci USA 100:98-103

Kammel M, Kern J, Lubitz W, Bittl R (2003) Photosystem II single crystals studied by transient EPR: the light-induced triplet state. Biochim Biophys Acta 1605:47-54

Kanan MW, Nocera DG (2008) In situ formation of an oxygen-evolving catalyst in neutral water containing phosphate and $\mathrm{Co}^{2+}$. Science 321:1072-1075

Karge M, Irrgang KD, Renger G (1997) Analysis of the reaction coordinate of photosynthetic water oxidation by kinetic measurements of $355 \mathrm{~nm}$ absorption changes at different temperatures in photosystem II preparations suspended in either $\mathrm{H}_{2} \mathrm{O}$ or $\mathrm{D}_{2} \mathrm{O}$. Biochemistry 36:8904-8913

Kawamori A, Inui T, Ono T, Inoue Y (1989) Endor study on the position of hydrogens close to the manganese cluster in $\mathrm{S}_{2}$ state of photosystem II. FEBS Lett 254:219-224

Kawashima K, Takaoka T, Kimura H, Saito K, Ishikita H (2018) $\mathrm{O}_{2}$ evolution and recovery of the water-oxidizing enzyme. Nat Commun 9:1247. https://doi.org/10.1038/s41467-018-03545-w

Kern J et al (2012) Room temperature femtosecond X-ray diffraction of photosystem II microcrystals. Proc Natl Acad Sci USA 109:9721-9726

Kern J et al (2013) Simultaneous femtosecond X-ray spectroscopy and diffraction of photosystem II at room temperature. Science 340:491-495

Kern J et al (2014) Taking snapshots of photosynthetic water oxidation using femtosecond X-ray diffraction and spectroscopy. Nat Commun 5:4371. https://doi.org/10.1038/ncomms5371

Kern J et al (2018) Structures of the intermediates of Kok's photosynthetic water oxidation clock. Nature 563:421-425

Kim CJ, Debus RJ (2017) Evidence from FTIR difference spectroscopy that a substrate $\mathrm{H}_{2} \mathrm{O}$ molecule for $\mathrm{O}_{2}$ formation in photosystem II is provided by the $\mathrm{Ca}$ ion of the catalytic $\mathrm{Mn}_{4} \mathrm{CaO}_{5}$ cluster. Biochemistry 56:2558-2570

Kim CJ, Bao H, Burnap RL, Debus RJ (2018) Impact of D1-V185 on the water molecules that facilitate $\mathrm{O}_{2}$ formation by the 
catalytic $\mathrm{Mn}_{4} \mathrm{CaO}_{5}$ cluster in photosystem II. Biochemistry 57:4299-4311

Klauss A, Haumann M, Dau H (2012a) Alternating electron and proton transfer steps in photosynthetic water oxidation. Proc Natl Acad Sci USA 109:16035-16040

Klauss A, Sikora T, Suss B, Dau H (2012b) Fast structural changes (200-900 ns) may prepare the photosynthetic manganese complex for oxidation by the adjacent tyrosine radical. Biochim Biophys Acta 1817:1196-1207

Klauss A, Haumann M, Dau H (2015) Seven steps of alternating electron and proton transfer in photosystem II water oxidation traced by time-resolved photothermal beam deflection at improved sensitivity. J Phys Chem B 119:2677-2689

Kok B, Forbush B, Mcgloin M (1970) Cooperation of charges in photosynthetic $\mathrm{O}_{2}$ evolution 1. A linear 4 step mechanism. Photochem Photobiol 11:457-475

Kolling DR, Cox N, Ananyev GM, Pace RJ, Dismukes GC (2012) What are the oxidation states of manganese required to catalyze photosynthetic water oxidation? Biophys J 103:313-322

Koua FHM, Umena Y, Kawakami K, Shen J-R (2013) Structure of Sr-substituted photosystem II at $2.1 \AA$ resolution and its implications in the mechanism of water oxidation. Proc Natl Acad Sci USA 110:3889-3894

Krewald V, Neese F, Pantazis DA (2013) On the magnetic and spectroscopic properties of high-valent $\mathrm{Mn}_{3} \mathrm{CaO}_{4}$ cubanes as structural units of natural and artificial water-oxidizing catalysts. J Am Chem Soc 135:5726-5739

Krewald V et al (2015) Metal oxidation states in biological water splitting. Chem Sci 6:1676-1695

Krewald V, Retegan M, Neese F, Lubitz W, Pantazis DA, Cox N (2016) Spin state as a marker for the structural evolution of nature's water splitting catalyst. Inorg Chem 55:488-501

Kulik L, Epel B, Messinger J, Lubitz W (2005a) Pulse EPR, ${ }^{55} \mathrm{Mn}$ ENDOR and ELDOR-detected NMR of the $\mathrm{S}_{2}$ state of the oxygen evolving complex in photosystem II. Photosynth Res 84:347-353

Kulik LV, Epel B, Lubitz W, Messinger J (2005b) ${ }^{55} \mathrm{Mn}$ pulse ENDOR at $34 \mathrm{GHz}$ of the $S_{0}$ and $S_{2}$ states of the oxygen-evolving complex in photosystem II. J Am Chem Soc 127:2392-2393

Kulik LV, Epel B, Lubitz W, Messinger J (2007) Electronic structure of the $\mathrm{Mn}_{4} \mathrm{O}_{\mathrm{x}}$ Ca cluster in the $\mathrm{S}_{0}$ and $\mathrm{S}_{2}$ states of the oxygen-evolving complex of photosystem II based on pulse ${ }^{55} \mathrm{Mn}$ ENDOR and EPR spectroscopy. J Am Chem Soc 129:13421-13435

Kupitz C et al (2014) Serial time-resolved crystallography of photosystem II using a femtosecond X-ray laser. Nature 513:261-265

Kurz P (2016) Biomimetic water-oxidation catalysts: manganese oxides. In: Tüysüz H, Chan CK (eds) Solar energy for fuels. Topics in current chemistry, vol 371. Springer, Cham, pp 49-72

Li X, Siegbahn PEM (2015) Alternative mechanisms for $\mathrm{O}_{2}$ release and $\mathrm{O}-\mathrm{O}$ bond formation in the oxygen evolving complex of photosystem II. Phys Chem Chem Phys 17:12168-12174

Linke K, Ho FM (2014) Water in Photosystem II: structural, functional and mechanistic considerations. Biochim Biophys Acta 1837:14-32

Lohmiller T, Cox N, Su J-H, Messinger J, Lubitz W (2012) The basic properties of the electronic structure of the oxygen-evolving complex of photosystem II are not perturbed by $\mathrm{Ca}^{2+}$ removal. J Biol Chem 287:24721-24733

Lohmiller T, Ames W, Lubitz W, Cox N, Misra SK (2013) EPR Spectroscopy and the electronic structure of the oxygen-evolving complex of photosystem II. Appl Magn Reson 44:691-720

Lohmiller T et al (2014) Structure, ligands and substrate coordination of the oxygen-evolving complex of photosystem II in the $\mathrm{S}_{2}$ state: a combined EPR and DFT study. Phys Chem Chem Phys 16:11877-11892
Lohmiller T et al (2017) The first state in the catalytic cycle of the water-oxidizing enzyme: identification of a water-derived $\mu$-hydroxo bridge. J Am Chem Soc 139:14412-14424

Luber $\mathrm{S}$ et al (2011) $\mathrm{S}_{1}$ state model of the $\mathrm{O}_{2}$ evolving complex of photosystem II. Biochemistry 50:6308-6311

Macpherson AN, Telfer A, Barber J, Truscott TG (1993) Direct detection of singlet oxygen from isolated photosystem II reaction centers. Biochim Biophys Acta 1143:301-309

Marchiori DA, Oyala PH, Debus RJ, Stich TA, Britt RD (2018) Structural effects of ammonia binding to the $\mathrm{Mn}_{4} \mathrm{CaO}_{5}$ cluster of photosystem II. J Phys Chem B 122:1588-1599

Matheu R, Garrido-Barros P, Gil-Sepulcre M, Ertem MZ, Sala X, Gimbert-Suriñach C, Llobet A (2019) The development of molecular water oxidation catalysts. Nat Rev Chem 3:331-341

McConnell IL, Grigoryants VM, Scholes CP, Myers WK, Chen P-Y, Whittaker JW, Brudvig GW (2012) EPR-ENDOR characterization of $\left({ }^{17} \mathrm{O},{ }^{1} \mathrm{H},{ }^{2} \mathrm{H}\right)$ water in manganese catalase and its relevance to the oxygen-evolving complex of photosystem II. J Am Chem Soc 134:1504-1512

McKone JR, Crans DC, Martin C, Turner J, Duggal AR, Gray HB (2016) Translational science for energy and beyond. Inorg Chem 55:9131-9143

Messinger J (2004) Evaluation of different mechanistic proposals for water oxidation in photosynthesis on the basis of $\mathrm{Mn}_{4} \mathrm{O}_{\mathrm{x}} \mathrm{Ca}$ structures for the catalytic site and spectroscopic data. Phys Chem Chem Phys 6:4764-4771

Messinger J, Renger G (2008) Photosynthetic water splitting. In: Renger G (ed) Primary processes of photosynthesis, Part 2: principles and apparatus. RSC Publishing, Cambridge, UK, pp 291-349

Messinger J, Badger M, Wydrzynski T (1995) Detection of one slowly exchanging substrate water molecule in the $\mathrm{S}_{3}$ state of photosystem-II. Proc Natl Acad Sci USA 92:3209-3213

Messinger J, Robblee JH, Yu WO, Sauer K, Yachandra VK, Klein MP (1997) The $S_{0}$ state of the oxygen-evolving complex in photosystem II is paramagnetic: detection of EPR multiline signal. $\mathrm{J}$ Am Chem Soc 119:11349-11350

Messinger $\mathbf{J}$ et al (2001) Absence of Mn-centered oxidation in the $\mathrm{S}_{2} \rightarrow \mathrm{S}_{3}$ transition: implications for the mechanism of photosynthetic water oxidation. J Am Chem Soc 123:7804-7820

Messinger J, Lubitz W, Shen JR (eds) (2014) Special issue: photosynthesis: from natural to artificial. Phys Chem Chem Phys 24

Michel H (1982) 3-dimensional crystals of a membrane-protein complex - the photosynthetic reaction center from Rhodopseudomonas viridis. J Mol Biol 158:567-572

Michel H (1983) Crystallization of membrane proteins. Trends Biochem Sci 8:56-59

Michel H (2008) Die natürliche Photosynthese: Ihre Effizienz und die Konsequenzen. In: Gruss P, Schüth F (eds) Die Zukunft der Energie. C.H.Beck, München, pp 71-85

Miqyass M, Marosvolgyi MA, Nagel Z, Yocum CF, van Gorkom HJ (2008) S-state dependence of the calcium requirement and binding characteristics in the oxygen-evolving complex of photosystem II. Biochemistry 47:7915-7924

Murray JW, Barber J (2007) Structural characteristics of channels and pathways in photosystem II including the identification of an oxygen channel. J Struct Biol 159:228-237

Nagashima H, Mino H (2013) Highly resolved proton matrix ENDOR of oriented photosystem II membranes in the $\mathrm{S}_{2}$ state. Biochim Biophys Acta 1827:1165-1173

Najafpour MM et al (2016) Manganese compounds as water-oxidizing catalysts: from the natural water-oxidizing complex to nanosized manganese oxide structures. Chem Rev 116:2886-2936

Nakamura S, Ota K, Shibuya Y, Noguchi T (2016) Role of a water network around the $\mathrm{Mn}_{4} \mathrm{CaO}_{5}$ cluster in photosynthetic water oxidation: a fourier transform infrared spectroscopy and quantum 
mechanics/molecular mechanics calculation study. Biochemistry 55:597-607

Nilsson H, Rappaport F, Boussac A, Messinger J (2014) Substratewater exchange in photosystem II is arrested before dioxygen formation. Nat Commun 5:4305. https://doi.org/10.1038/ncomm s5305

Nilsson H, Cournac L, Rappaport F, Messinger J, Lavergne J (2016) Estimation of the driving force for dioxygen formation in photosynthesis. Biochim Biophys Acta 1857:23-33

Nixon PJ, Michoux F, Yu JF, Boehm M, Komenda J (2010) Recent advances in understanding the assembly and repair of photosystem II. Ann Bot 106:1-16

Nocera DG (2012) The artificial leaf. Acc Chem Res 45:767-776

Nocera DG (2017) Solar fuels and solar chemicals industry. Acc Chem Res 50:616-619

Noguchi T (2008) FTIR detection of water reactions in the oxygen-evolving centre of photosystem II. Philos Trans R Soc B 363:1189-1195

Noguchi T, Suzuki H, Tsuno M, Sugiura M, Kato C (2012) Timeresolved infrared detection of the proton and protein dynamics during photosynthetic oxygen evolution. Biochemistry 51:3205-3214

Nugent JHA, Muhiuddin IP, Evans MCW (2002) Electron transfer from the water oxidizing complex at cryogenic temperatures: The $S_{1}$ to $S_{2}$ step. Biochemistry 41:4117-4126

Ono TA, Nakayama H, Gleiter H, Inoue Y, Kawamori A (1987) Modification of the properties of $\mathrm{S}_{2}$ state in photosynthetic $\mathrm{O}_{2}$ evolving center by replacement of chloride with other anions. Arch Biochem Biophys 256:618-624

Ono TA, Noguchi T, Inoue Y, Kusunoki M, Matsushita T, Oyanagi $\mathrm{H}$ (1992) X-ray detection of the period-four cycling of the manganese cluster in photosynthetic water oxidizing enzyme. Science 258:1335-1337

Oyala PH, Stich TA, Stull JA, Yu F, Pecoraro VL, Britt RD (2014) Pulse electron paramagnetic resonance studies of the interaction of methanol with the $\mathrm{S}_{2}$ state of the $\mathrm{Mn}_{4} \mathrm{O}_{5} \mathrm{Ca}$ cluster of photosystem II. Biochemistry 53:7914-7928

Oyala PH, Stich TA, Debus RJ, Britt RD (2015) Ammonia binds to the dangler manganese of the photosystem II oxygen-evolving complex. J Am Chem Soc 137:8829-8837

Pace RJ, Smith P, Bramley R, Stehlik D (1991) Epr saturation and temperature dependence studies on signals from the oxygenevolving center of photosystem II. Biochim Biophys Acta 1058:161-170

Pantazis DA (2018) Missing pieces in the puzzle of biological water oxidation. ACS Catal 8:9477-9507

Pantazis DA, Orio M, Petrenko T, Zein S, Lubitz W, Messinger J, Neese F (2009) Structure of the oxygen-evolving complex of photosystem II: information on the $\mathrm{S}_{2}$ state through quantum chemical calculation of its magnetic properties. Phys Chem Chem Phys 11:6788-6798

Pantazis DA, Ames W, Cox N, Lubitz W, Neese F (2012) Two interconvertible structures that explain the spectroscopic properties of the oxygen-evolving complex of photosystem II in the $\mathrm{S}_{2}$ state. Angew Chem Int Ed 51:9935-9940

Pecoraro VL, Baldwin MJ, Caudle MT, Hsieh WY, Law NA (1998) A proposal for water oxidation in photosystem II. Pure Appl Chem 70:925-929

Peloquin JM, Britt RD (2001) EPR/ENDOR characterization of the physical and electronic structure of the OEC Mn cluster. Biochim Biophys Acta 1503:96-111

Peloquin JM, Campbell KA, Britt RD (1998) ${ }^{55} \mathrm{Mn}$ pulsed ENDOR demonstrates that the photosystem II "split" EPR signal arises from a magnetically-coupled mangano-tyrosyl complex. J Am Chem Soc 120:6840-6841
Peloquin JM, Campbell KA, Randall DW, Evanchik MA, Pecoraro VL, Armstrong WH, Britt RD (2000) ${ }^{55} \mathrm{Mn}$ ENDOR of the $\mathrm{S}_{2}$ state multiline EPR signal of photosystem II: implications on the structure of the tetranuclear Mn cluster. J Am Chem Soc 122:10926-10942

Perez-Navarro M et al (2013) Ammonia binding to the oxygen-evolving complex of photosystem II identifies the solvent-exchangeable oxygen bridge (mu-oxo) of the manganese tetramer. Proc Natl Acad Sci USA 110:15561-15566

Perez-Navarro M, Neese F, Lubitz W, Pantazis DA, Cox N (2016) Recent developments in biological water oxidation. Curr Opin Chem Biol 31:113-119

Petrouleas V, Koulougliotis D, Ioannidis N (2005) Trapping of metalloradical intermediates of the S-states at liquid helium temperatures. Overview of the phenomenology and mechanistic implications. Biochemistry 44:6723-6728

Planavsky NJ et al (2014) Evidence for oxygenic photosynthesis half a billion years before the great oxidation event. Nat Geosci 7:283-286

Rapatskiy L et al (2012) Detection of the water-binding sites of the oxygen-evolving complex of photosystem II using W-band ${ }^{17} \mathrm{O}$ electron-electron double resonance-detected NMR spectroscopy. J Am Chem Soc 134:16619-16634

Rapatskiy L et al (2015) Characterization of oxygen bridged manganese model complexes using multifrequency ${ }^{17} \mathrm{O}$ hyperfine EPR spectroscopies and density functional theory. J Phys Chem B 119:13904-13921

Rappaport F, Blancharddesce M, Lavergne J (1994) Kinetics of electron-transfer and electrochromic change during the redox transitions of the photosynthetic oxygen-evolving complex. Biochim Biophys Acta 1184:178-192

Rappaport F, Guergova-Kuras M, Nixon PJ, Diner BA, Lavergne J (2002) Kinetics and pathways of charge recombination in photosystem II. Biochemistry 41:8518-8527

Razeghifard MR, Pace RJ (1997) Electron paramagnetic resonance kinetic studies of the S states in spinach PSII membranes. Biochim Biophys Acta 1322:141-150

Retegan M, Pantazis DA (2016) Interaction of methanol with the oxygen-evolving complex: atomistic models, channel identification, species dependence, and mechanistic implications. Chem Sci 7:6463-6476

Retegan M, Pantazis DA (2017) Differences in the active site of water oxidation among photosynthetic organisms. J Am Chem Soc 139:14340-14343

Retegan M, Cox N, Lubitz W, Neese F, Pantazis DA (2014) The first tyrosyl radical intermediate formed in the $S_{2}-S_{3}$ transition of photosystem II. Phys Chem Chem Phys 16:11901-11910

Retegan M, Krewald V, Mamedov F, Neese F, Lubitz W, Cox N, Pantazis DA (2016) A five-coordinate Mn(IV) intermediate in biological water oxidation: spectroscopic signature and a pivot mechanism for water binding. Chem Sci 7:72-84

Robblee JH, Cinco RM, Yachandra VK (2001) X-ray spectroscopybased structure of the Mn cluster and mechanism of photosynthetic oxygen evolution. Biochim Biophys Acta 1503:7-23

Robblee JH et al (2002) The Mn cluster in the $\mathrm{S}_{0}$ state of the oxygenevolving complex of photosystem II studied by EXAFS spectroscopy: are there three di-mu-oxo-bridged $\mathrm{Mn}_{2}$ moieties in the tetranuclear Mn complex? J Am Chem Soc 124:7459-7471

Romain S, Vigara L, Llobet A (2009) Oxygen-oxygen bond formation pathways promoted by ruthenium complexes. Acc Chem Res 42:1944-1953

Saito K, Shen JR, Ishida T, Ishikita H (2011) Short hydrogen bond between redox-active tyrosine $\mathrm{Yz}$ and D1-His 190 in the photosystem II crystal structure. Biochemistry 50:9836-9844

Saito T et al (2012) Possible mechanisms of water splitting reaction based on proton and electron release pathways revealed for 
$\mathrm{CaMn}_{4} \mathrm{O}_{5}$ cluster of PSII refined to $1.9 \AA \mathrm{X}$-ray resolution. Int $\mathrm{J}$ Quantum Chem 112:253-276

Sakamoto H, Shimizu T, Nagao R, Noguchi T (2017) Monitoring the reaction process during the $\mathrm{S} 2-\mathrm{S} 3$ transition in photosynthetic water oxidation using time-resolved infrared spectroscopy. J Am Chem Soc 139:2022-2029

Sanakis Y, Sarrou J, Zahariou G, Petrouleas V (2008) Q-band electron paramagnetic resonance studies of the $\mathrm{S}_{3}$ state of the OEC of photosystem II. Photosynthesis. Energy from the sun: 14th international congress on photosynthesis, pp 479-482

Schlodder E, Witt HT (1999) Stoichiometry of proton release from the catalytic center in photosynthetic water oxidation: reexamination by a glass electrode study at $\mathrm{pH}$ 5.5-7.2. J Biol Chem 274:30387-30392

Schraut J, Kaupp M (2014) On ammonia binding to the oxygen-evolving complex of photosystem II: a quantum chemical study. Chem Eur J 20:7300-7308

Schweiger A, Jeschke G (2001) Principles of pulse electron paramagnetic resonance. Oxford University Press, Oxford

Service RJ, Hillier W, Debus RJ (2014) Network of hydrogen bonds near the oxygen-evolving $\mathrm{Mn}_{4} \mathrm{CaO}_{5}$ cluster of photosystem II probed with FTIR difference spectroscopy. Biochemistry 53:1001-1017

Shen J-R (2015) The structure of photosystem II and the mechanism of water oxidation in photosynthesis. Annu Rev Plant Biol 66:23-48

Shoji M, Isobe H, Shigeta Y, Nakajima T, Yamaguchi K (2018) Nonadiabatic one-electron transfer mechanism for the $\mathrm{O}-\mathrm{O}$ bond formation in the oxygen-evolving complex of photosystem II. Chem Phys Lett 698:138-146

Siegbahn PEM (2009) Structures and energetics for $\mathrm{O}_{2}$ formation in photosystem II. Acc Chem Res 42:1871-1880

Siegbahn PEM (2012) Mechanisms for proton release during water oxidation in the $S_{2}$ to $S_{3}$ and $S_{3}$ to $S_{4}$ transitions in photosystem II. Phys Chem Chem Phys 14:4849-4856

Stich TA, Yeagle GJ, Service RJ, Debus RJ, Britt RD (2011) Ligation of D1-His332 and D1-Asp170 to the manganese cluster of photosystem II from Synechocystis assessed by multifrequency pulse EPR spectroscopy. Biochemistry 50:7390-7404

Stull JA, Stich TA, Service RJ, Debus RJ, Mandal SK, Armstrong WH, Britt RD (2010) ${ }^{13} \mathrm{C}$ ENDOR reveals that the D1 polypeptide $\mathrm{C}$-terminus is directly bound to $\mathrm{Mn}$ in the photosystem II oxygen evolving complex. J Am Chem Soc 132:446-447

Styring S, Feyziyev Y, Mamedov F, Hillier W, Babcock GT (2003) pH dependence of the donor side reactions in $\mathrm{Ca}^{2+}$-depleted photosystem II. Biochemistry 42:6185-6192

Styring S, Sjoholm J, Mamedov F (2012) Two tyrosines that changed the world: interfacing the oxidizing power of photochemistry to water splitting in photosystem II. Biochim Biophys Acta 1817:76-87

Su JH et al (2011) The electronic structures of the $S_{2}$ states of the oxygen-evolving complexes of photosystem II in plants and cyanobacteria in the presence and absence of methanol. Biochim Biophys Acta 1807:829-840

Suga M et al (2015) Native structure of photosystem II at 1.95 ̊ resolution viewed by femtosecond X-ray pulses. Nature 517:99-103

Suga $M$ et al (2017) Light-induced structural changes and the site of $\mathrm{O}=\mathrm{O}$ bond formation in PSII caught by XFEL. Nature 543:131-135

Suzuki H, Sugiura M, Noguchi T (2008) Monitoring water reactions during the S-state cycle of the photosynthetic water-oxidizing center: detection of the DOD bending vibrations by means of Fourier transform infrared spectroscopy. Biochemistry 47:11024-11030

Suzuki H, Sugiura M, Noguchi T (2009) Monitoring proton release during photosynthetic water oxidation in Photosystem II by means of isotope-edited infrared spectroscopy. J Am Chem Soc 131:7849-7857

Tagore R, Chen HY, Crabtree RH, Brudvig GW (2006) Determination of $\mu$-oxo exchange rates in di- $\mu$-oxo dimanganese complexes by electrospray ionization mass spectrometry. J Am Chem Soc 128:9457-9465

Tagore R, Crabtree RH, Brudvig GW (2007) Distinct mechanisms of bridging-oxo exchange in di- $\mu$-O dimanganese complexes with and without water-binding sites: Implications for water binding in the $\mathrm{O}_{2}$-evolving complex of photosystem II. Inorg Chem 46:2193-2203

Terrett R, Petrie S, Stranger R, Pace RJ (2016) What computational chemistry and magnetic resonance reveal concerning the oxygen evolving centre in photosystem II. J Inorg Biochem 162:178-189

Tran PD, Wong LH, Barber J, Loo JSC (2012) Recent advances in hybrid photocatalysts for solar fuel production. Energy Environ Sci 5:5902-5918

Ugur I, Rutherford AW, Kaila VRI (2016) Redox-coupled substrate water reorganization in the active site of Photosystem II-The role of calcium in substrate water delivery. Biochim Biophys Acta 1857:740-748

Umena Y, Kawakami K, Shen J-R, Kamiya N (2011) Crystal structure of oxygen-evolving photosystem II at a resolution of $1.9 \AA$. Nature 473:55-60

Vass I (2012) Molecular mechanisms of photodamage in the photosystem II complex. Biochim Biophys Acta 1817:209-217

Vassiliev S, Zaraiskaya T, Bruce D (2012) Exploring the energetics of water permeation in photosystem II by multiple steered molecular dynamics simulations. Biochim Biophys Acta 1817:1671-1678

Vinyard DJ, Brudvig GW (2017) Progress toward a molecular mechanism of water oxidation in photosystem II. Annu Rev Phys Chem 68:101-116

Vinyard DJ, Khan S, Brudvig GW (2015) Photosynthetic water oxidation: binding and activation of substrate waters for $\mathrm{O}-\mathrm{O}$ bond formation. Faraday Discuss 185:37-50

Vrettos JS, Limburg J, Brudvig GW (2001a) Mechanism of photosynthetic water oxidation: combining biophysical studies of photosystem II with inorganic model chemistry. Biochim Biophys Acta 1503:229-245

Vrettos JS, Stone DA, Brudvig GW (2001b) Quantifying the ion selectivity of the $\mathrm{Ca}^{2+}$ site in photosystem II: evidence for direct involvement of $\mathrm{Ca}^{2+}$ in $\mathrm{O}_{2}$ formation. Biochemistry 40:7937-7945

Weil JA, Bolton JR (2007) Electron paramagnetic resonance: elementary theory and practical applications. Wiley, Hoboken

Wydrzynski TJ, Hillier W (eds) (2012) Molecular solar fuels. RSC energy and environment series, vol 5. RSC Pub., Royal Society of Chemistry (Great Britain), Cambridge

Wydrzynski T, Satoh K (eds) (2005) Photosystem II, the light-driven water: plastoquinone oxidoreductase. Springer, Dordrecht

Yachandra VK, Sauer K, Klein MP (1996) Manganese cluster in photosynthesis: where plants oxidize water to dioxygen. Chem Rev 96:2927-2950

Yachandra VK, Yano J (2011) Calcium in the oxygen-evolving complex: structural and mechanistic role determined by X-ray spectroscopy. J Photochem Photobiol B 104:51-59

Yano J, Yachandra V (2014) $\mathrm{Mn}_{4} \mathrm{Ca}$ cluster in photosynthesis: where and how water is oxidized to dioxygen. Chem Rev 114:4175-4205

Yano J et al (2005) X-ray damage to the $\mathrm{Mn}_{4} \mathrm{Ca}$ complex in single crystals of photosystem II: a case study for metalloprotein crystallography. Proc Natl Acad Sci USA 102:12047-12052

Yano J et al (2006) Where water is oxidized to dioxygen: Structure of the photosynthetic $\mathrm{Mn}_{4} \mathrm{Ca}$ cluster. Science 314:821-825 
Young ID et al (2016) Structure of photosystem II and substrate binding at room temperature. Nature 540:453-457

Zaharieva I, Chernev P, Berggren G, Anderlund M, Styring S, Dau H, Haumann M (2016a) Room-temperature energy-sampling K beta $\mathrm{X}$-ray emission spectroscopy of the $\mathrm{Mn}_{4} \mathrm{Ca}$ complex of Photosynthesis reveals three manganese-centered oxidation steps and suggests a coordination change prior to $\mathrm{O}_{2}$ formation. Biochemistry 55:4197-4211

Zaharieva I, Dau H, Haumann M (2016b) Sequential and coupled proton and electron transfer events in the S2-S3 transition of photosynthetic water oxidation revealed by time-resolved X-ray absorption spectroscopy. Biochemistry 55:6996-7004

Zhang B, Sun L (2018) Why nature chose the $\mathrm{Mn}_{4} \mathrm{CaO}_{5}$ cluster as water-splitting catalyst in photosystem II: a new hypothesis for the mechanism of $\mathrm{O}-\mathrm{O}$ bond formation. Dalton Trans 47:14381-14387
Zhang C, Chen C, Dong H, Shen J-R, Dau H, Zhao J (2015) A synthetic $\mathrm{Mn}_{4} \mathrm{Ca}$-cluster mimicking the oxygen-evolving center of photosynthesis. Science 348:690-693

Zimmermann JL, Rutherford AW (1984) Electron-paramagnetic-res studies of the oxygen-evolving enzyme of photosystem II. Biochim Biophys Acta 767:160-167

Zouni A, Witt HT, Kern J, Fromme P, Krauss N, Saenger W, Orth P (2001) Crystal structure of photosystem II from Synechococcus elongatus at 3.8 Å resolution. Nature 409:739-743

Publisher's Note Springer Nature remains neutral with regard to jurisdictional claims in published maps and institutional affiliations. 